This article has been scanned by iThenticat No plagiarism detected

Volume 3, Issue 5, October 2021

p. 371-392

\title{
APPLIED LINGUISTIC APPROACH TO TEACHING FOREIGN LANGUAGES THEORETICAL AND METHODOLOGICAL MODELS
}

http://dx.doi.org/10.47832/2757-5403.5-3.32

Latifa Mohamed ALAHYANE' 1

\begin{abstract}
:
The theoretical achievement in the field of foreign language learning in the 1950s and early 1960s remained related to the practical side of language teaching. Moreover, The idea of the need for foreign language teaching methodologies for a theory of learning has remained constant since the occurrence of educational reform movements of the late nineteenth century.

To come to terms with the current developments in the field of foreign language learning, it is necessary to trace the recent history of the research carried out in this regard. Therefore, we will focus in this article on tracking the most important theoretical assets of foreign language teaching methods, and monitoring the evolution of language teaching and learning methods. This is done to distinguish between two approaches to language teaching; first, Direct teaching that negates the overlap of the learned and acquired language during foreign language instruction. And second Mediated teaching in which the second language is taught through the first language. Through this, we will monitor the cognitive cross-fertilization between acquiring the first language and learning the second one by tracing the relationship between them. We will list the most important assumptions underpinned by approaches to foreign language teaching. And we will monitor the foundations on which each approach is based separately to discover the commonalities between them and the contrast between them.

We will then contribute to building a new conception of foreign language learning by making use of the translation action inherent in the procedures adopted in most of these approaches. This is mainly evident in the difference between the necessity of adopting the first language or not during the teaching and learning of the foreign language.
\end{abstract}

\footnotetext{
${ }^{1}$ Dr. , Morocco, latifa.alahyane@edu.uiz.ac.ma, https://orcid.org/0000-0002-5964-4850
}

Copyright $(\mathcal{C}$ Published by IJHER Journal, www.ijherjournal.com Rimar Academy, Fatih, Istanbul, 34093 Turkey

All rights reserved 


\section{APPLIED LINGUISTIC APPROACH TO TEACHING FOREIGN \\ LANGUAGES THEORETICAL AND METHODOLOGICAL MODELS}

Key words: Applied Linguistics, First Language acquisition, Teaching Foreign Languages approaches, Direct teaching, Mediated teaching.

\section{المقاربة اللسانية التطبيقية لتعليم اللغات الأجنبية نماذج نظرية ومنهجية التطية}

\section{لطيفة محمد ألحيان 2}

ظل المنجز النظري في ميدان تعلم اللغة الأجنبية في مرحلة الخمسينيات وأوائل الستينيات

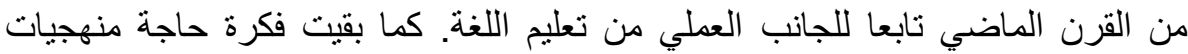

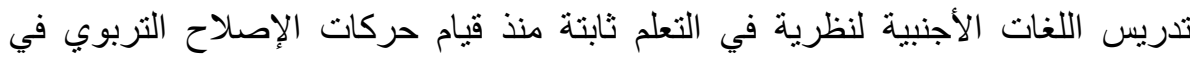

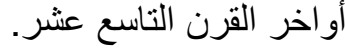

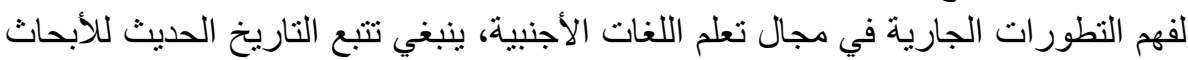

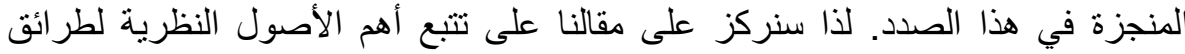

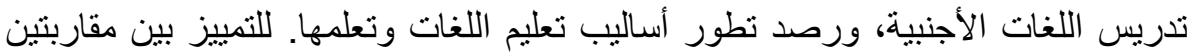
اثثتين في تعليم اللغات؛ التعليم المباثر الذي ينفي تداخل اللغة المتعلمة واللغة التئة المكتسبة أثناء

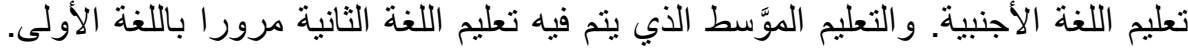

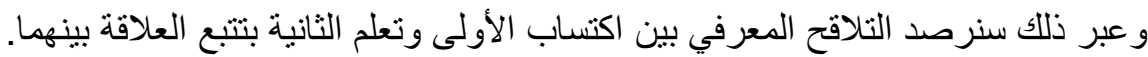

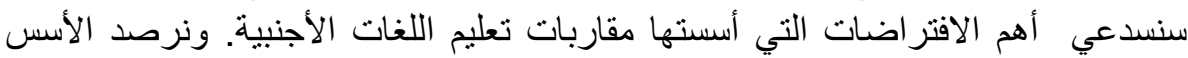
التي ترتكز عليها كل مقاربة على حدة لاكتشاف القو اسم المشتركة بينها و التباين القائم بينها.

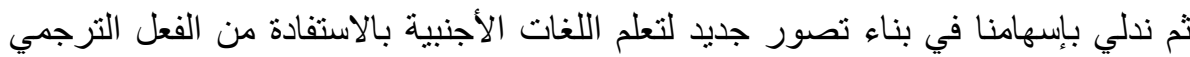

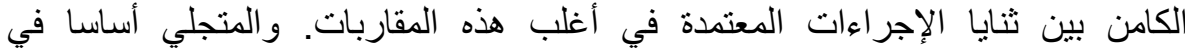
الاختلاف بين ضرورة اعتماد اللغة الأولى أو عدم اعتمادها أثناء تعليم اللغة الأجنيبة وتعلمها. الكلمات المفتاحية: اللسانيات التطبيقية، اكتساب اللغة الأولى، مقاربات تعليم اللغات الأجنبية، التعليم المباشر، التعليم الموَّطط.

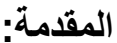

يستطيع الأطفال اكتساب لغتهم الأولى في وقت مبكر من حياتهم، وفي فترة زمنية قصيرة. وما نظريات التعلم بصفة عامة، وتعلم اللغة بشكل خاص، إلا اجتهادات من الباحثين لتفطن التعلم ومعرفة حقائقه. بيد أن تعلم اللغات الأجنبية خارج بيئتها الطبعية، ليس أمر ا سلسا. لذلك انشغل الباحثون المختصون بدراسة هذه الظاهرة، لاستجلاء طبيعتها وتحديد التباين بينها وبين تعلم اللغة الأولى. ظل المنجز النظري في ميدان تعلم اللغة الأجنيية في مرحلة الخمسينيات وأوائل الستينيات من القرن الماضي تابعا بشكل كبير للجانب العملي من تعليم اللغة. غير أن فكرة حاجة منهجيات تدريس اللغات الأجنبية لنظرية في التعلم كانت ثابتة مذ التئ

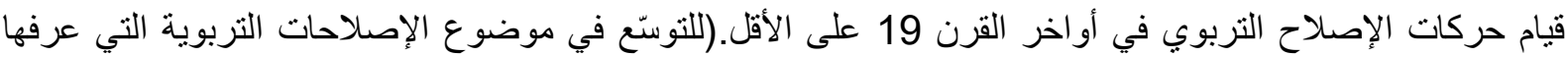
تعليم اللغة الإنجليزية لغة أجنبية في القرن التاسع عشر، ينظر: (A.P.R., Howatt., 1984, pp. 171-173)

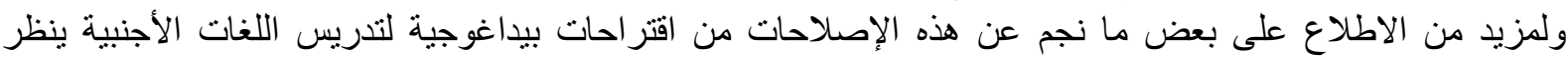

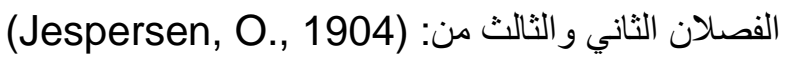




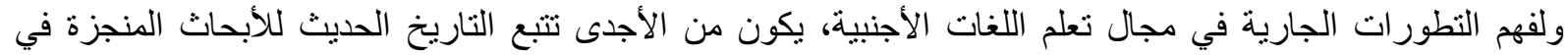

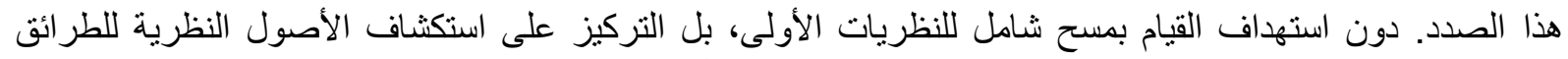

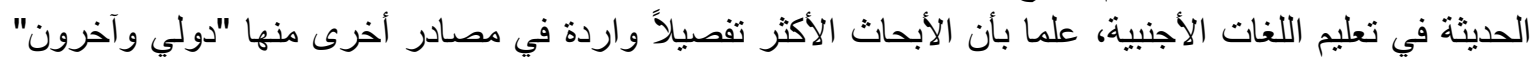
Larry Selinker Dulay, H. M. Burt, \& Krashen, S., 1982)

(Selinker, L, 1992)

\section{اكتساب اللغة الأولى وتعلم اللغة الأجنبية}

عرف مجال تعليم اللغات الاجنبية تغيرات عديدة، من تجلياتها اعتماد تسميات مختلفة. فأطلق على عملية تعليم

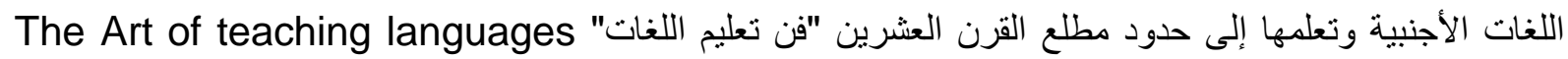

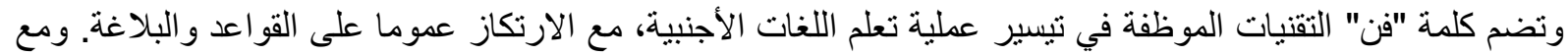

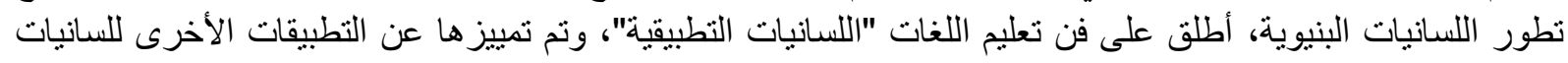

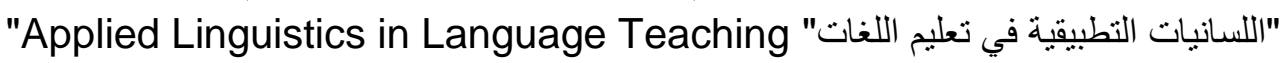

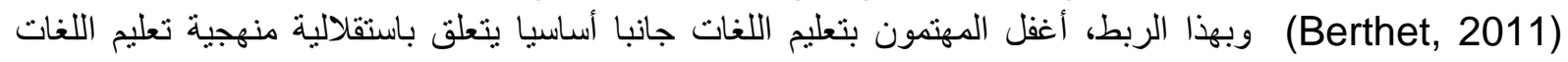

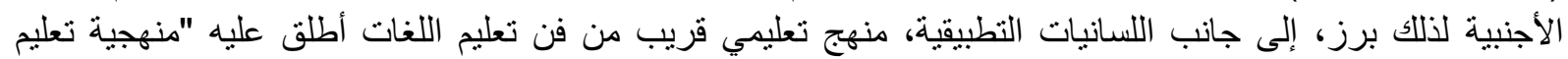

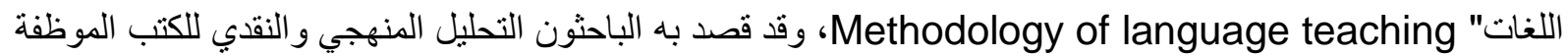

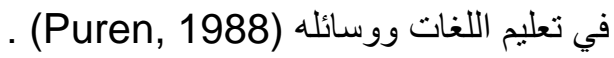
و على أساس أن تكامل مجالي اللسانيات ومنهجية تعليم اللغات الأجنبية، عُوضت التسمينان معا بثالثة هي؛ "ديداكتيك اللغات الأجنبية" Foreign language didactics. للاطلاع على تاريخ هذا التحول، وتفاصيله ينظر :

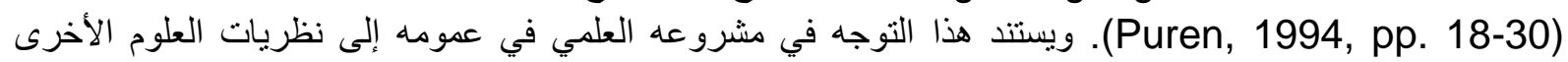

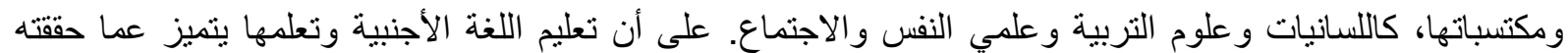

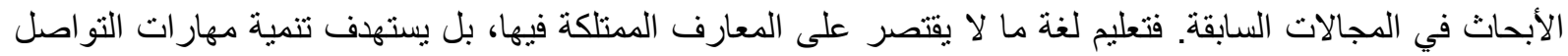

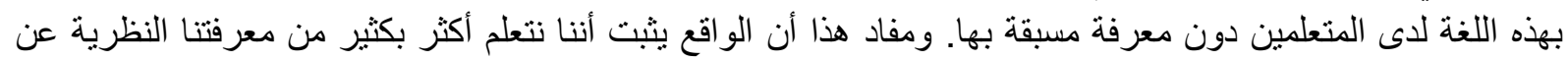

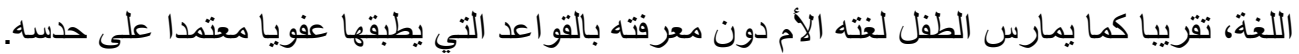

\section{المؤتلف والمختلف بين اكتساب اللغة الأولى وتعلم اللغة الأجنبية}

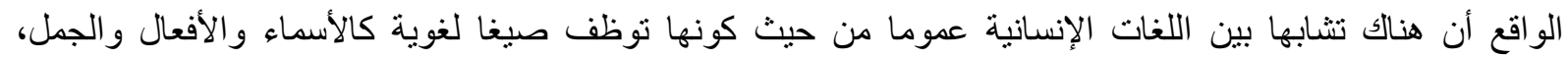

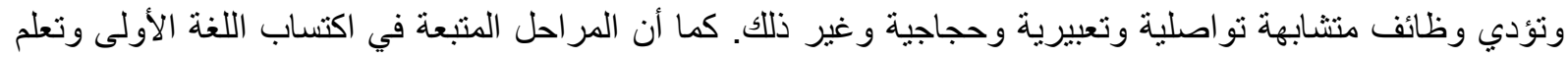

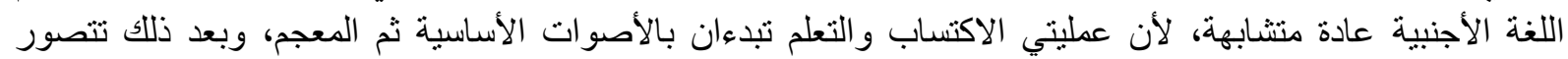

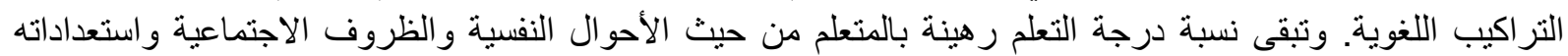

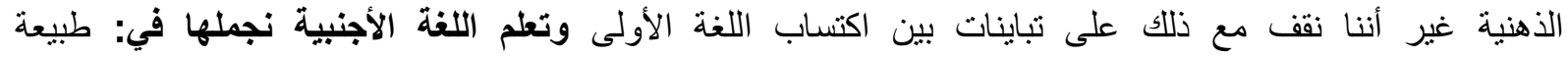

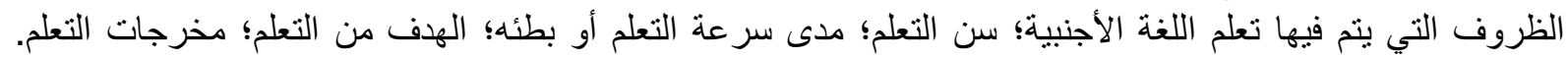
ينفرد اكتساب اللغة الأولى عن تعلم اللغة الأجنبية بكونه ينم في ظروف تلاف عادية وطبعية. فالطفل يكتسب لغته ويتقنها

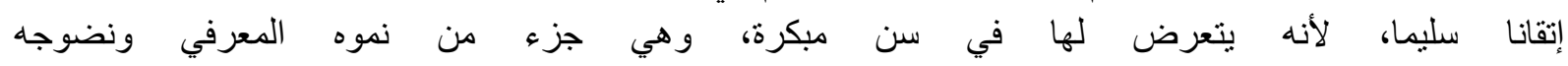

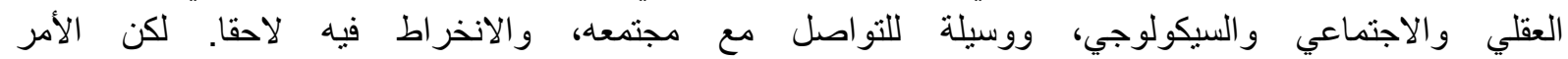

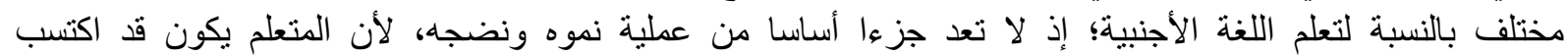

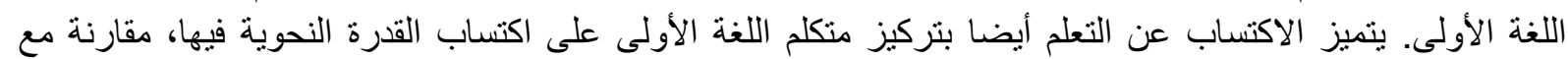

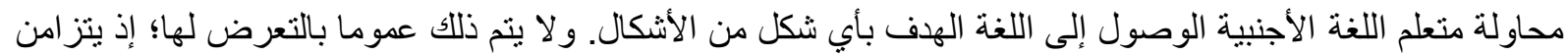

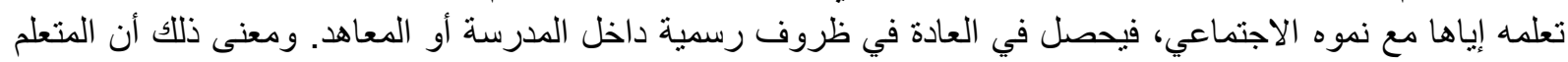

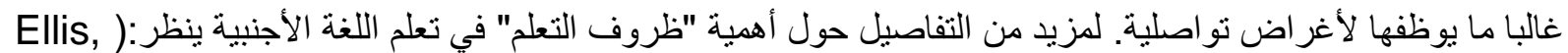

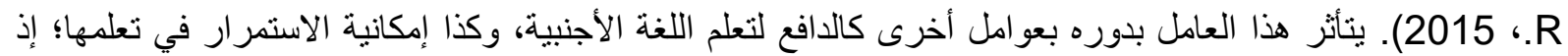

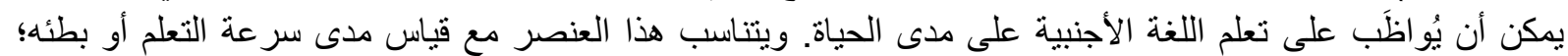
فيُعتقد أن السرعة التي يتم بها اكتساب اللغة الأولى عموما هي أكبر بكثير من التي تتعلم فيها اللغة الأجنبية. 


\section{APPLIED LINGUISTIC APPROACH TO TEACHING FOREIGN \\ LANGUAGES THEORETICAL AND METHODOLOGICAL MODELS}

كما يُفترض أن اللغة الأولى تكتسب بطريقة لا شعورية، بينما تُتَعَلَّم اللغة الأجنبية بطريقة إرادية، وغالبا ما تتم عملية التعلم في سن أكبر من التي تكتسب فيها اللغة الأولى. لذلك بعد عامل السن، الذي تُعُلَّم فيه اللغة الأجنبية، أحد

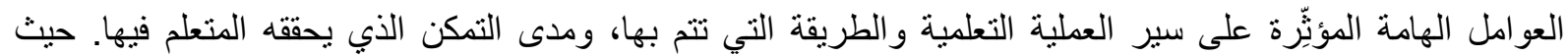

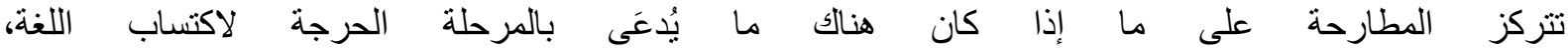

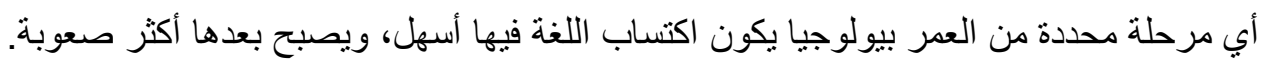

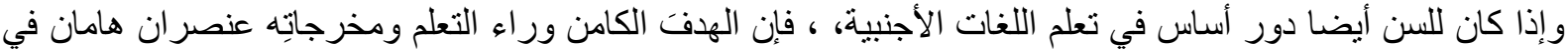

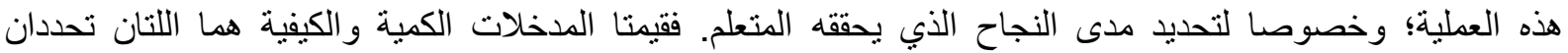

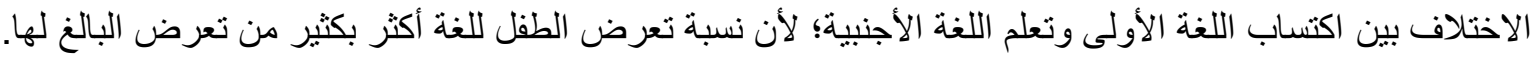

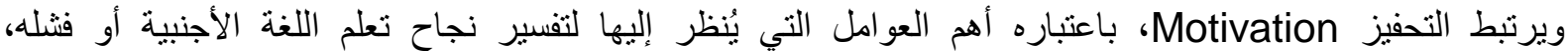

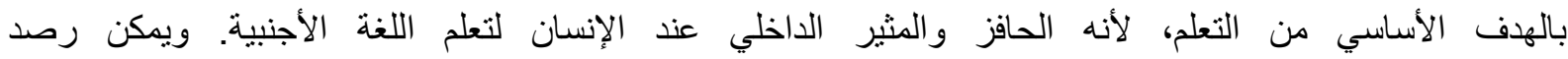
العديد من العو امل التعليمية و الفردية و الاجنماعية التي تؤثر في زيادة التهائ التحفيز أو الحد منه (Niklove, 2009, pp. 201-204) ومن بينها الذكاء و الاستعداد و المثابرة واستر اتيجيات التهات التعلم و التقويم الذاتي.

أهم مقاربات تعليم اللغات الأجنبية

تصدت دراسات عديدة، منذ عقود مضت للبحث في المشاكل التي تُصبّر تعلم اللغات الأجنبية عملية صعبة. ومن بين

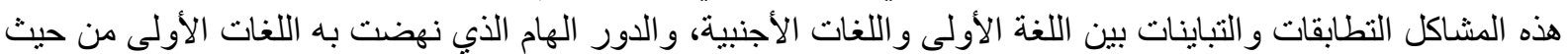

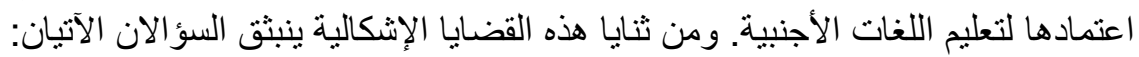

• هل تلعب اللغة الأولى دورا إيجابيا في عملية تعليم اللغة / اللغات الأجنبية؟

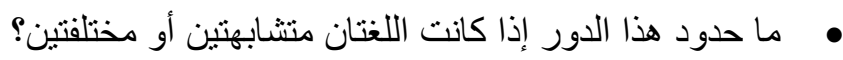

إذا استعرضنا تاريخ تعليم اللغات الأجنبية وجدناه لا يحيد عن إحدى الطريقتين: أـ الطريقة التقليدية التي عُدَّت سلبية لاستتادها إلى تلقين مفردات اللغة الأجنبية وقو اعدها وكذا تحفيظها؛ للمزيد من التفاصيل المتعلقة بطبيعة الطرق التقليدية وآلياتها ينظر : (Puren, 1988, pp. 18-25). ب-الطريقة الحديثة القائمة على ممارسة اللغة الأجنبية وتعليم قو اعدها بشكل ضمني.

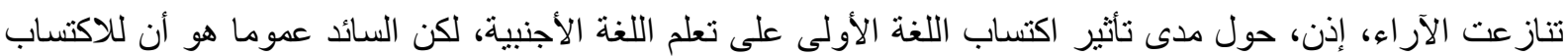

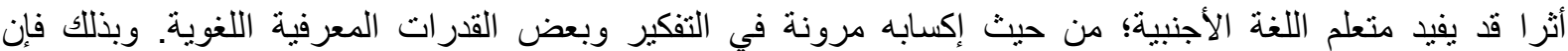
الأهم هو اعتبار اكتساب اللغة الأولى أحد العو امل المؤثرة في تعلم لغة أخرى.

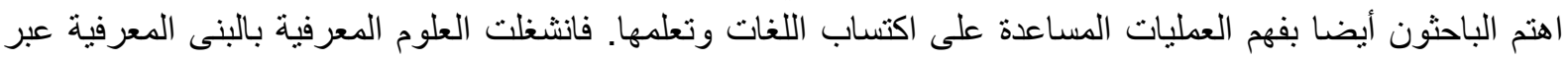
تحليل العمليات الذهنية التي يطبقها المتعلمون والمعالجة المعرفية للمعلومات. وحاولت البيداغوجيا فهم الاستراتيجيات

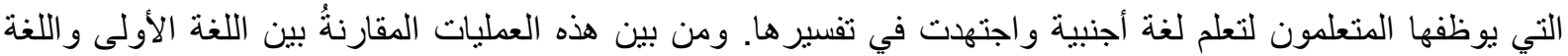

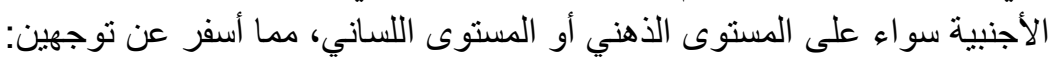

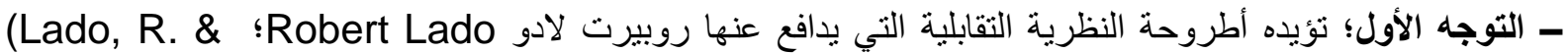

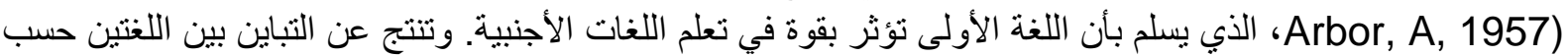

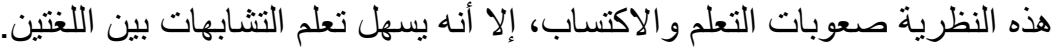

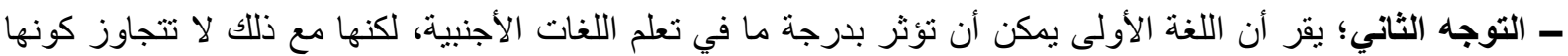

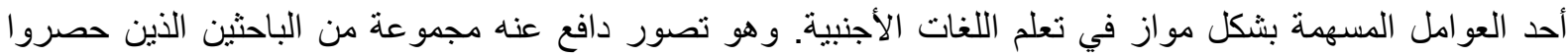
تخصصهم في مجال اكتساب اللغات الأجنبية وتعلمها ك: ستيفان كر اشن Krashen Stephne، ودولي هايدي ل

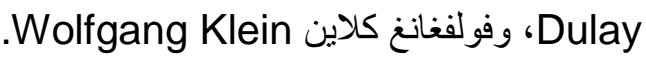


تستلهم فرضية التطابق Identity Hypothesis مبادئها من نظريات التعلم التي تتعارض مع النظرية

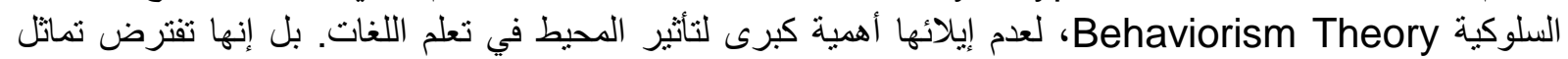

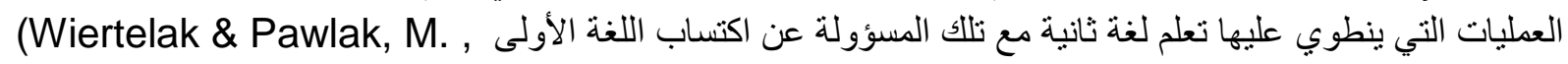

تعود المنطلقات التي تأسست عليها هذه المبادئ في أساسا إلى شومسكي Chomsky Noam استبعاده تأثير المحيط

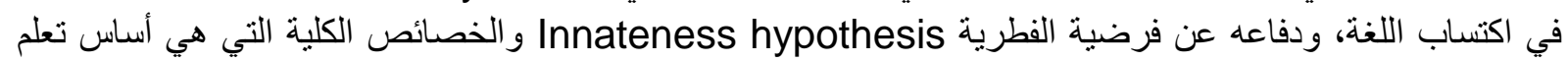

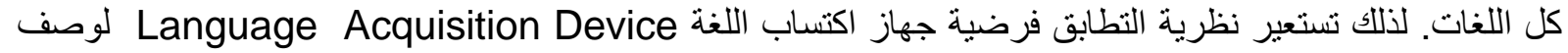

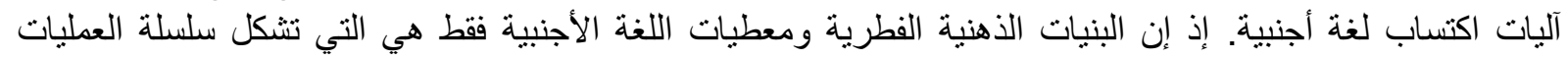

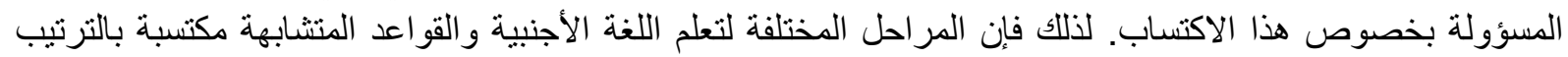

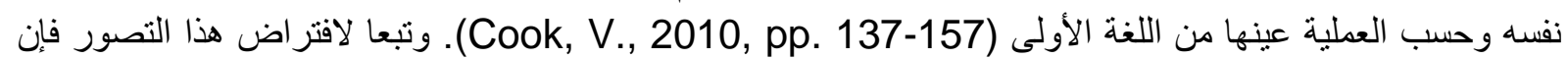
تعلم اللغات الأجنبية لا ينأثر بتاتا باللغة الأولنة الأولى.

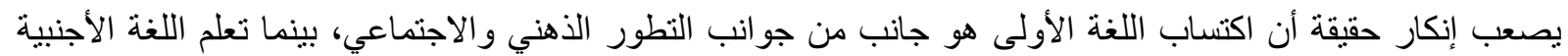

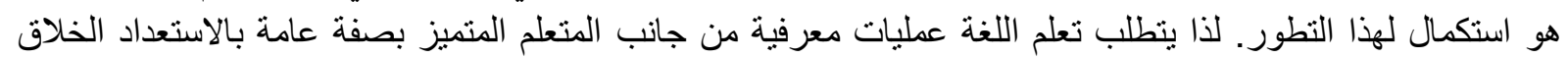

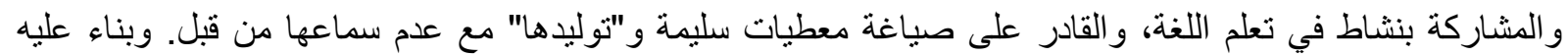

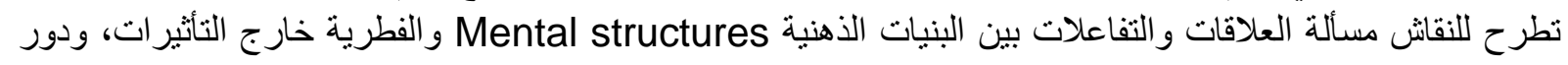

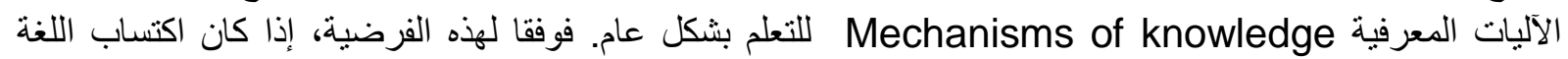

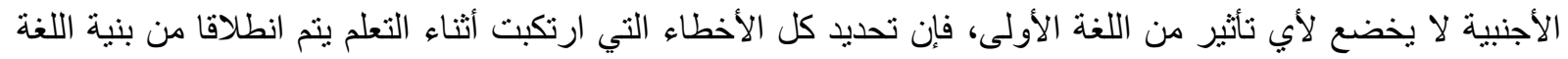

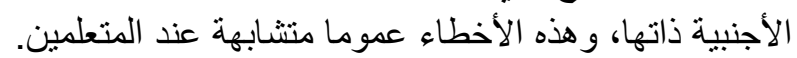

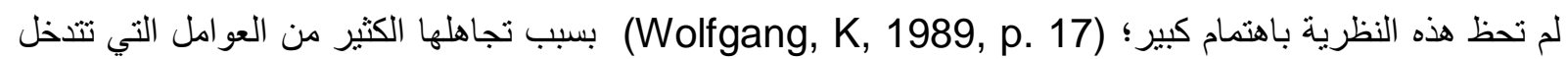

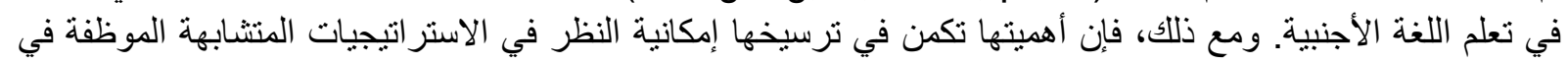

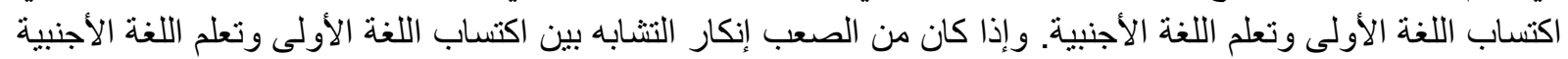

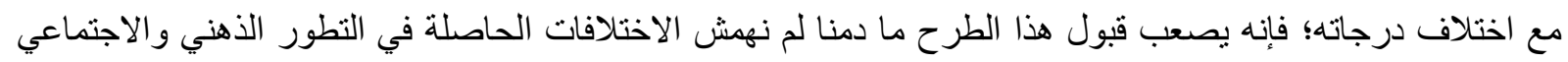

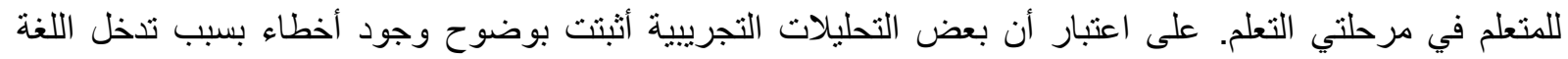
الأولى بمستو ياتها المختلفة عند تعلم اللغة أجنية.

\section{المقاربة التقابلية}

\section{فرضية التحليل التقابلي}

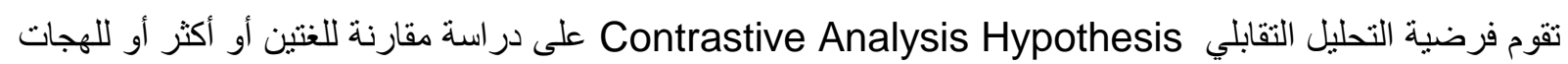

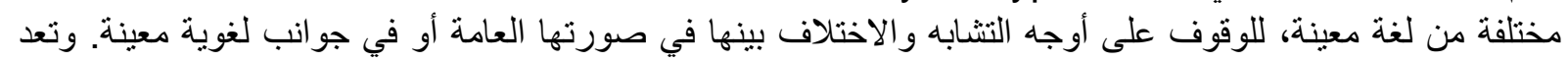

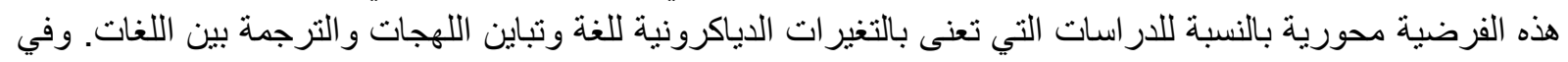

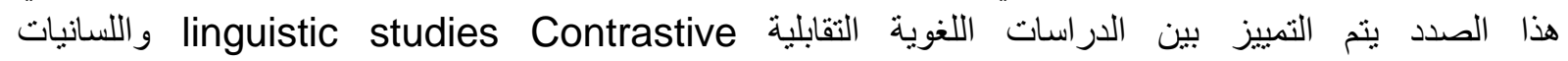

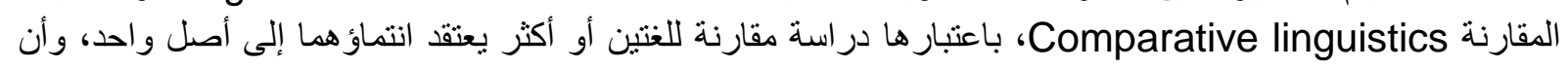

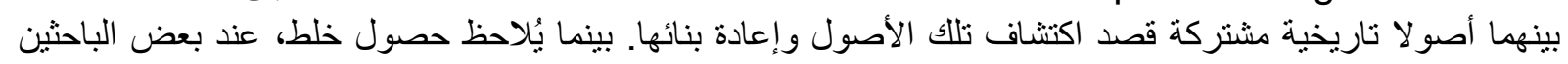

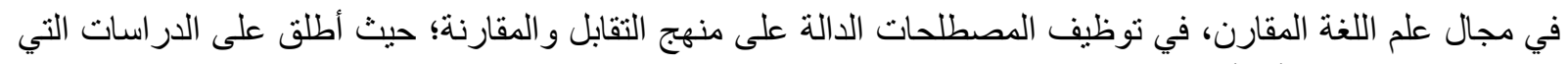

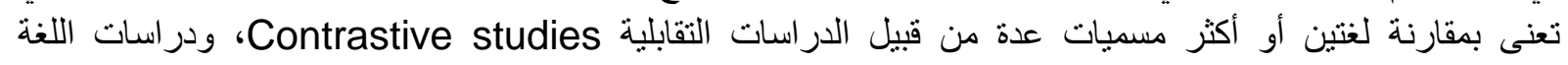

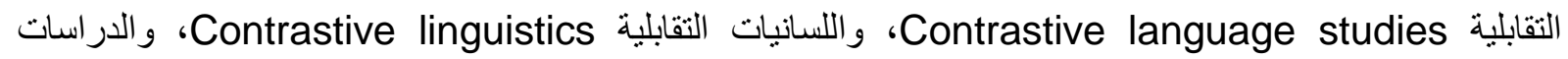

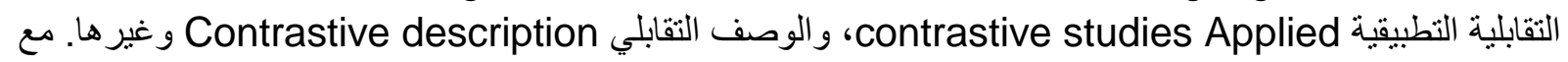

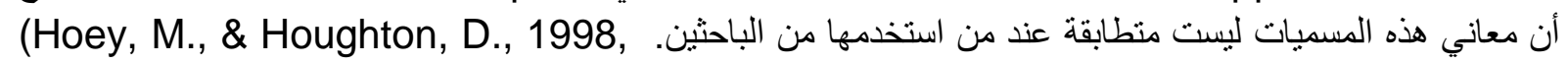

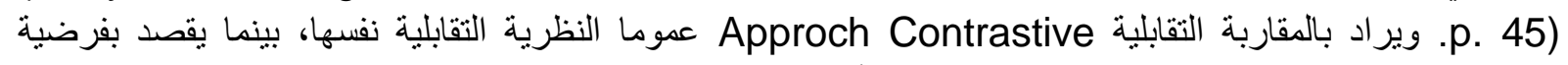

التحليل التقابلي المنهجية المعتمدة في تطبيق الفرضية، النية، أو النظرية والنطبيق معا. 


\section{APPLIED LINGUISTIC APPROACH TO TEACHING FOREIGN \\ LANGUAGES THEORETICAL AND METHODOLOGICAL MODELS}

على الرغم من الاختلاف في نشأة التحليل التقابلي، فإن معظم الدارسين يتفقون على أن البداية كانت منذ اعتماد هذه

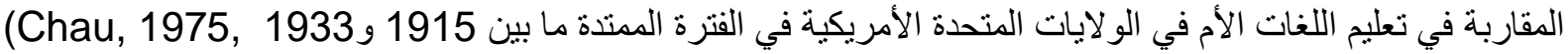
ولم تقتصر على هذا الصعيد فقط، بل نوسعت بعد ذلك في مجال تعليم اللغات الأجنبية بالبحث عن أسباب

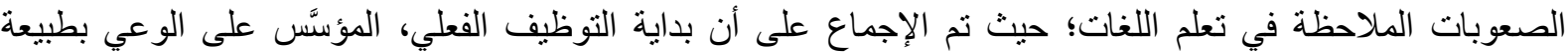

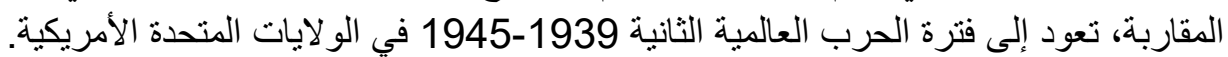
و إذا كان العديد من الباحثين في مجال بيداغوجيا تعليم اللغات، ومنهم هنري سويت Henry Sweet، وهائ وهارولد

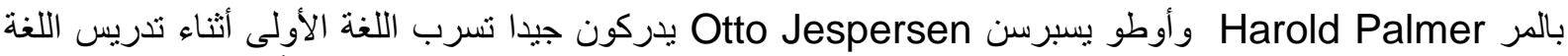

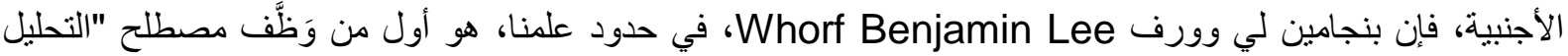
التقابلي" في مقال بعنوان "اللغة والمنطق" سنة 1941 (Joseph, 2004, pp. 71-72). مع أن تشارلز

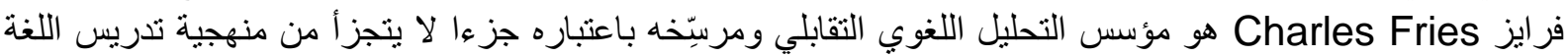

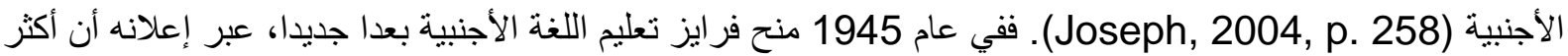

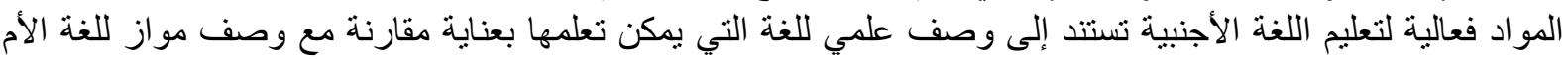

(Fries,C, 1945, p. 9) للمنعلم غير أن لادو هو من دفع بمقاربة التحليل التقابلي إلى الواجهة لدرجة اعتبرت معها مرجعا أساسا لمدرسي اللغة التها

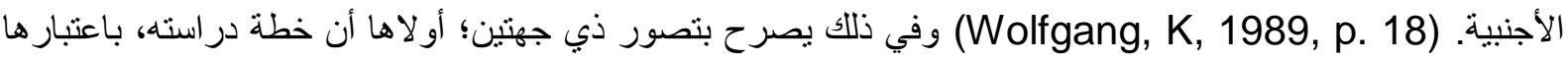

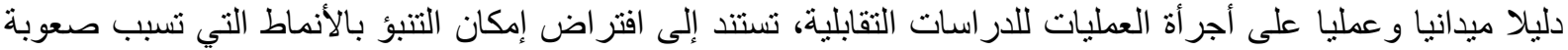

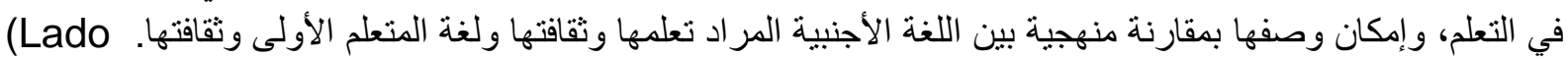
\& Arbor, 1957, p. preface)

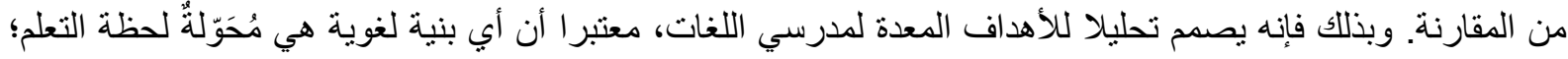

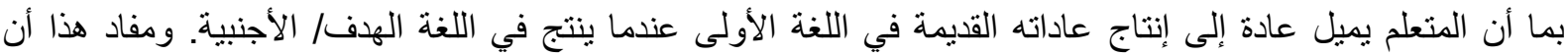
تأثثر اللغة الأولى يعد عاملا أصليا لتطوير تعليم اللغات (Lado, R. \& Arbor, A, 1957, p. 2).

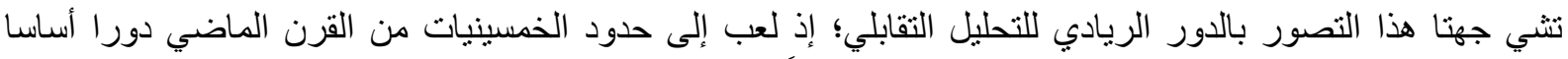

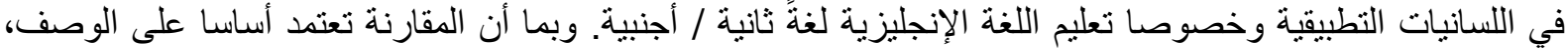

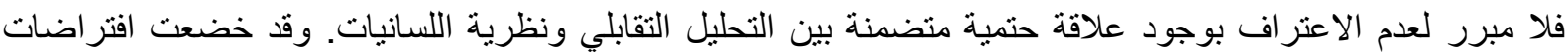

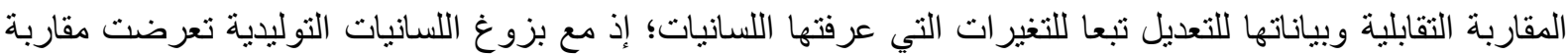
التحليل التقابلي للانتقادات، شأنها في ذلك شأن اللسانيات الوصفية، لانحسانية التحار انشغالها في البنية السطحية فقط. ومع ذلك فقد تأثر التحليل التقابلي بثلاثة جوانب أساسية في النحو التوليدي هي:

\section{فرضية النحو الكلي؛ التمييز بين البنية السطحية والبنية العميقة؛ الوصف الاقيق للظواهر اللغوية}

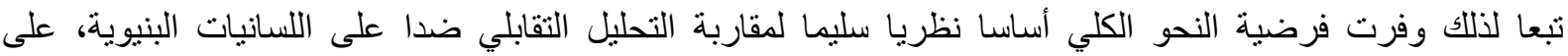

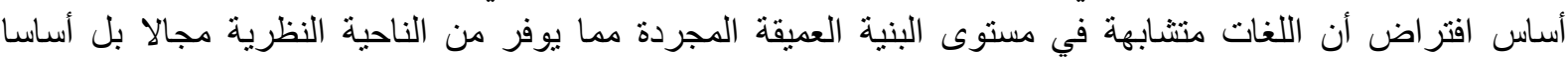
لل لممارسة التطبيقية للمقارنة.

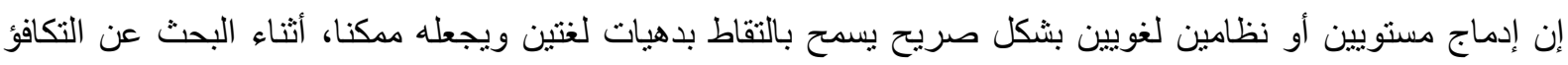

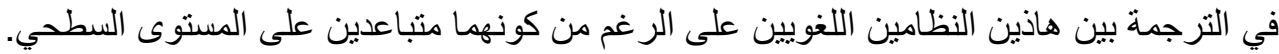

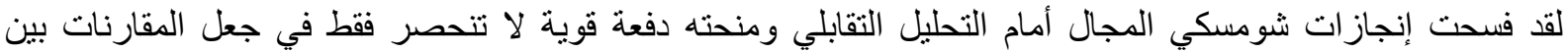
اللغات ممكنة، بل تمتد إلى نوفير أساس نظري متين عبر استلهام نظريته في الكليات اللغوية

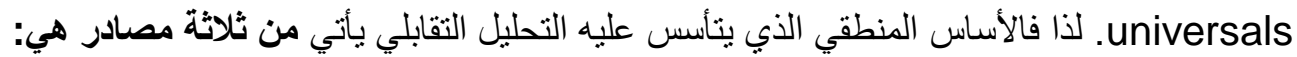
الخبرة العملية لمعلمي اللغات الأجنبية؛ دراسة الارتباط بين اللغات؛ نظريات التعلم

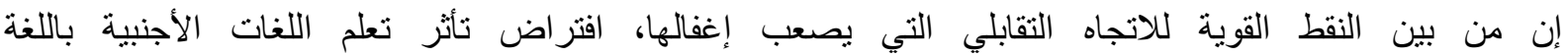

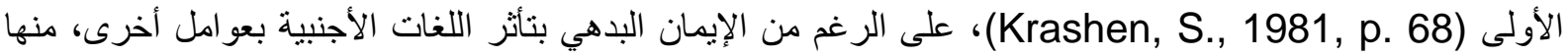

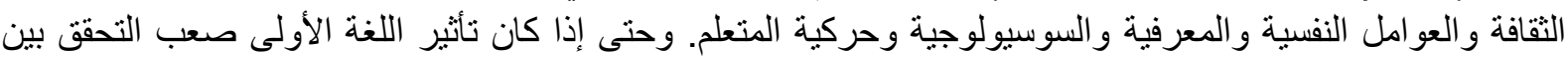

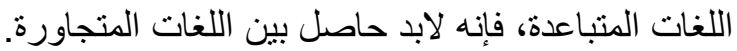


تدعم فرضية التحليل التقابلي بمصادر كثيرة؛ فمن جهة أولى، يلاحظ عموما أن غالبية مدرسي اللغات الأجنبية الذين

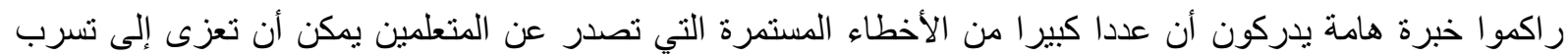

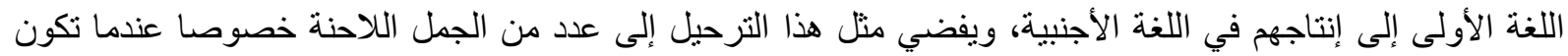

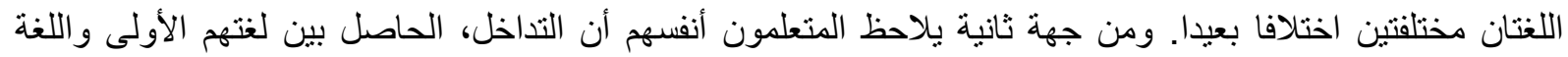

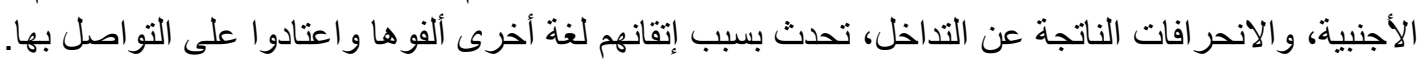

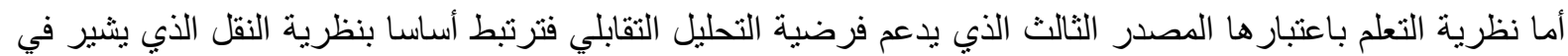

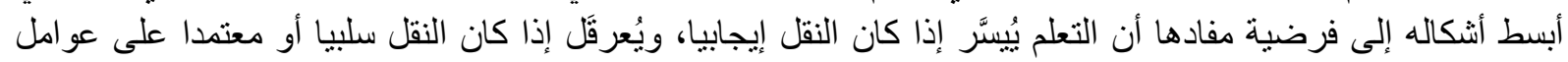

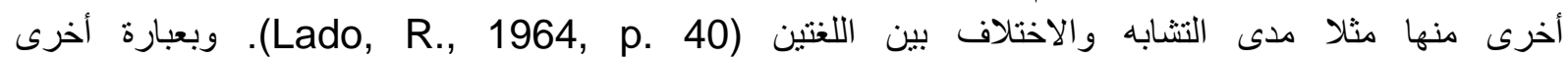

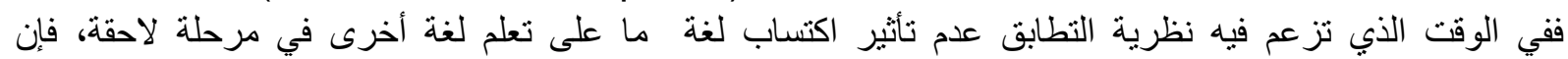

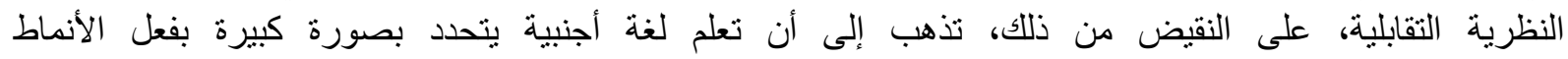

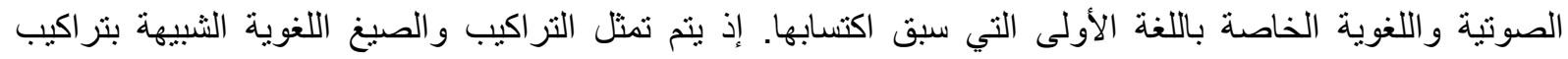

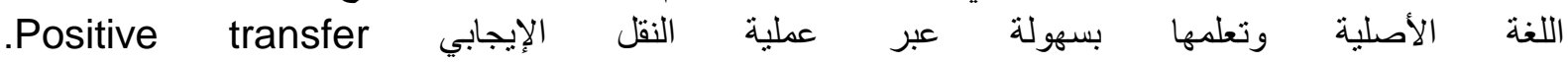
أما الصيخ والتراكيب المختلفة فتشكل عائقا أمام تعلم اللغة الأجنبية، وتسبب الفئ حدوث الأخطاء اللغوية نتيجة النقل

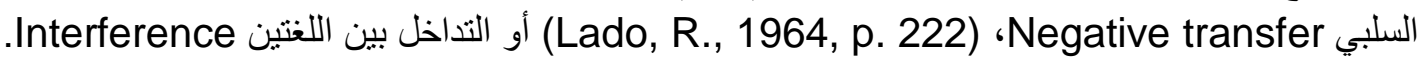
يختزل وليام رو لاند لـــee W.R. الفرضيات الأساسية التي ينبني عليها التحليل التقابلي في الآتي: ـ يتعين السبب الرئيس للصعوبات والأخطاء في اللغات الأجنبية في التداخل المتسرب من اللغة الأولى للمتعلم

\section{؛(Lee, W.R., 1968, p. 186)}

ـ تتحدد أسباب صعوبات التعلم أساسا وكليا في الاختلافات بين اللغتين؛

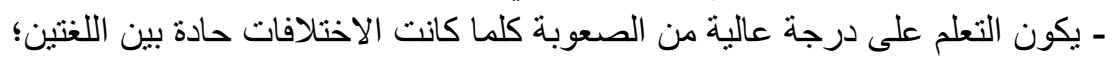

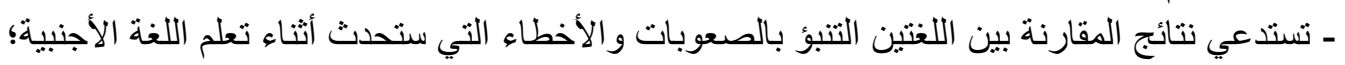

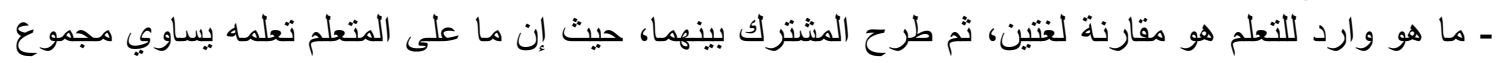
الاختلافات التي رصدها التحليل التقابلي (Lee, W.R., 1968, p. 180).

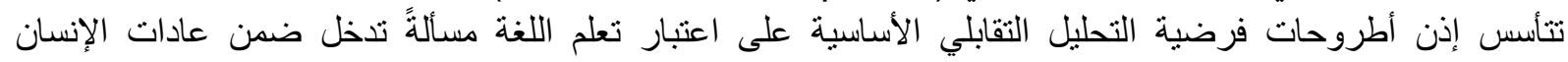

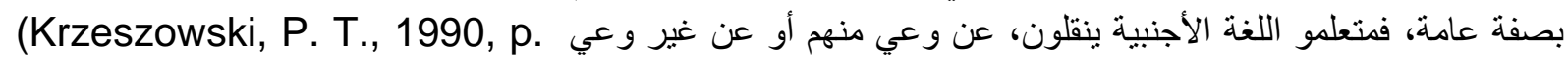

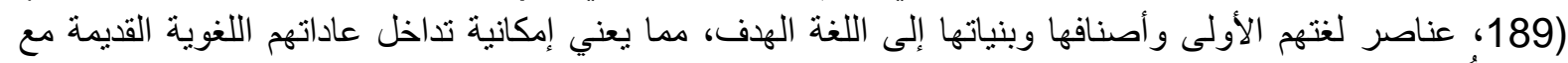

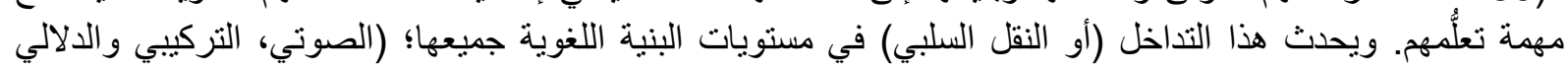
و التداولي)، ويؤثر على الإنتاج و المهار ات معا.

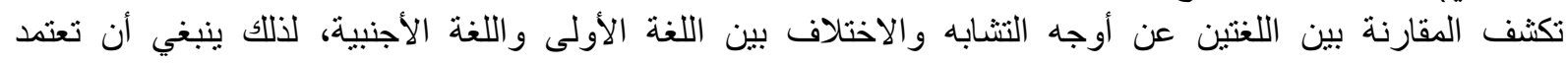

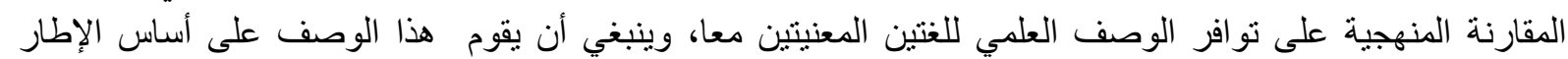

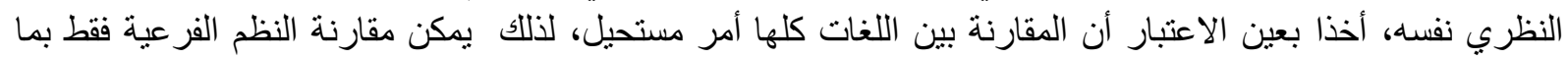

يعادلها. نتيجة لما سبق فإن التشابه بين اللغة الأولى واللغة الأجنبية لا بطرح أي مشاكل أثناء التعلم، على عكس الاخلافات التي

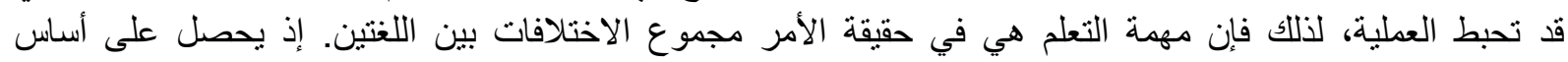

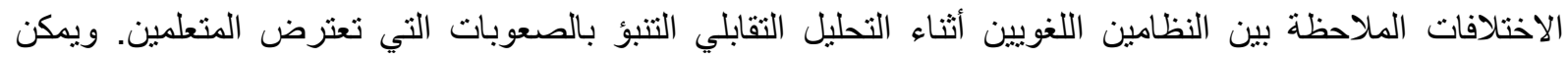

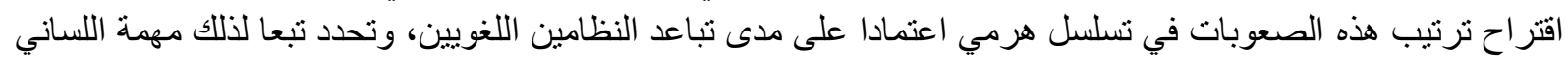

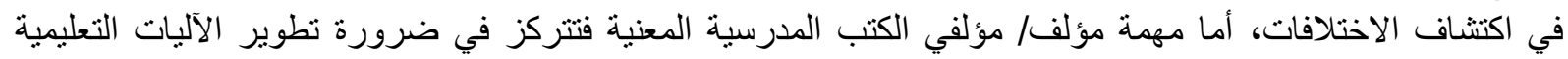
المناسبة. يستند التحليل التقابلي، إذن، إلى تو افر وصف دقيق ومقارنة واضحة بين اللغات نرتكز على إطار نظري منوافق، قصد

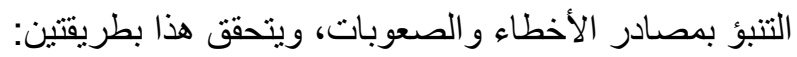

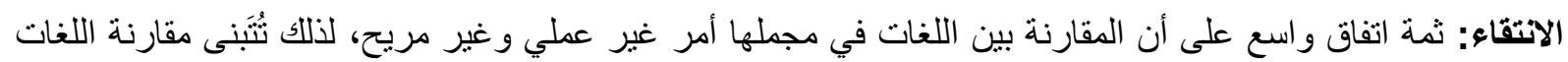

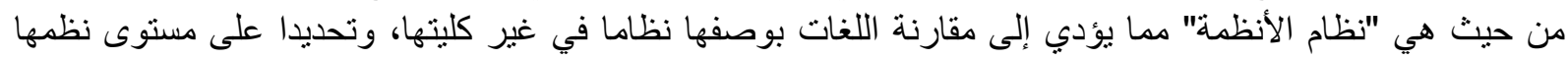
الفرعية. وبناء عليه تتم المقارنة على صعيد مستوى من المستويات فقط كالمستوى الصوتي الذي يمكن اختزاله الذه إلى 


\section{APPLIED LINGUISTIC APPROACH TO TEACHING FOREIGN \\ LANGUAGES THEORETICAL AND METHODOLOGICAL MODELS}

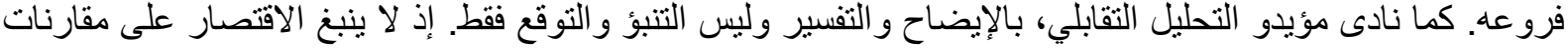

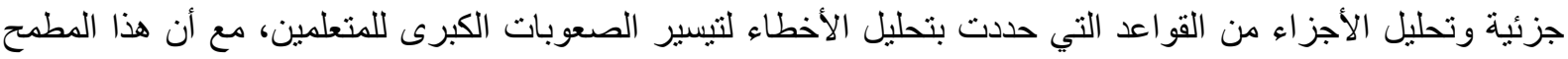
يصطدم بحالات ليست واردة بالضرورة في اللغة الأولى قد تعوق التحليل التقابلي. \& Boers, F., \&) .

Darquennes, J.R., 2007)

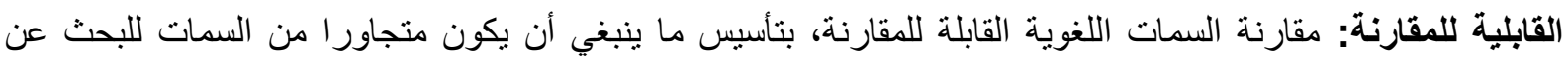
التكافؤ، وهي المشكلة التي أثنارت نقانشات عديدة بخصوص إمكانية إيجاد معادل واحد أو عدم إمكانية إيجاده. (سيقدم

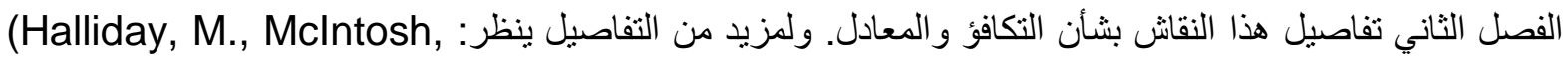

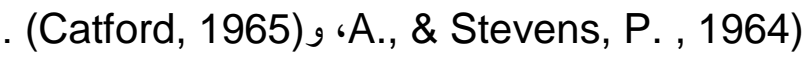
قارن لادو بين المصطلحات و البنى الخاصة باللغتنين (الأولى والأجنبية)، لكي يتنبأ بالصعوبات التي يمكن أن تحصل، ويتوقع الطرق التي يمكن أن تحل المشاكل و الصعوبات المبات المتعلقة بتعلم اللغات الأجنبية. ويورد ستيفان كوردر Stephen Corder الملاحظات التي يسجلها لادو على الثكل الآتي:

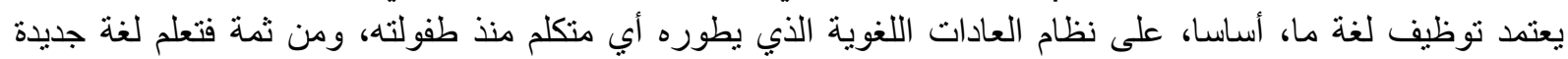
يتطلب نطوير نظام جديد للعادات (Corder, 1981, p. 10) يلاحظ إمكان التعرف على التر اكيب التي ينتجها المتعلمون باعتبار ها منتمية إلى اللغة الأولى، ومن ثم فبنية اللغة الأولى اللى الألى

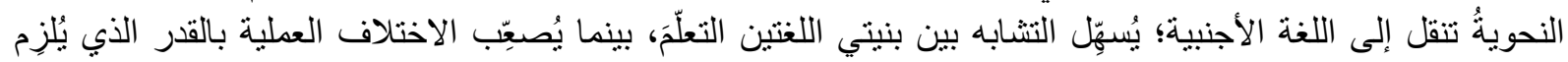
المتعلم تغيير عادات راسخة في سلوكه اللغوي، كما يصبح هذا الاختلاف مصدرا للنداخل بين اللغات. (Corder) 1981, p. 96) تفصح الملاحظتان الأولى والثانية عن نظرة مقيدة جدا لتعليم اللغات الأجنبية، لتهميشها عو امل أخرى مؤثرة على التعلم،

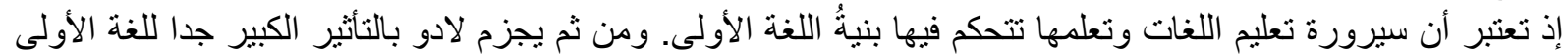

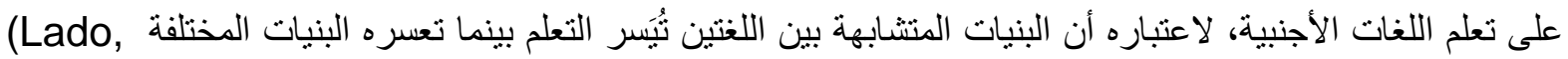
(R. \& Arbor, A, 1957, p. 59) غير أن هذا قد لا ينطبق على الأشكال جميعها وقد لا يحدث في المستويات كلها.

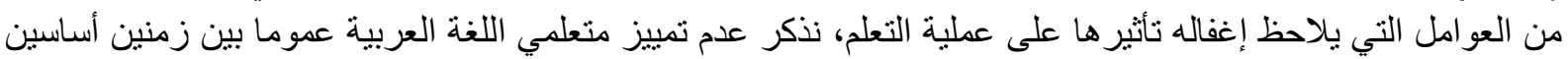

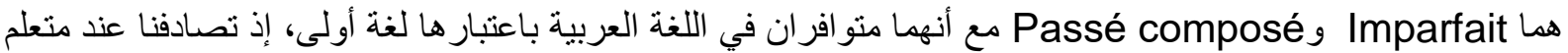

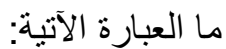

J'ai travaillé quand Ahmed est arrivé. -1

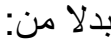

Je travaillais quand Ahmed est arrivé. -2 مع تحقق الزمنين معا في اللغة الأولى بصيغتين مختلفتين؛ إذ يمكن التعبير عن المثالين السابقين في اللغة العربية

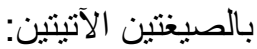
3- 3 اشتغلت عندما وصل أحمد. 4- كنت أثنتغل عندما وصل أحمد.

يبين المثالان السابقان، وغير هما كثير، أن نأثير اللغة الأولى ليس بالضرورة هو المسبب دوما في الارتباك، لأن الزمنين

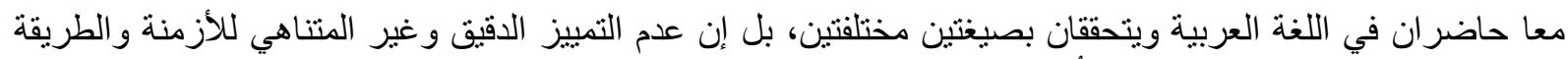

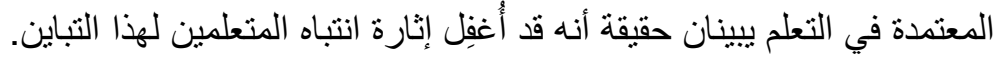

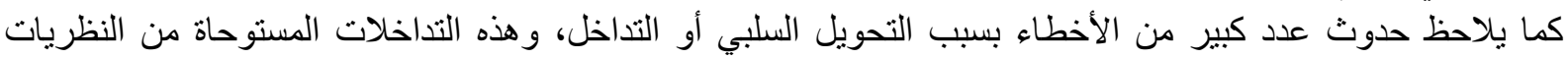

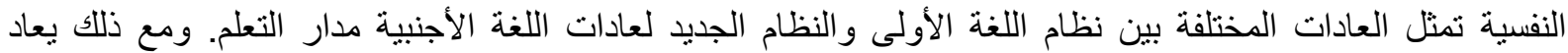

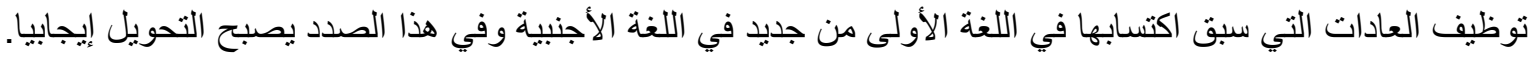

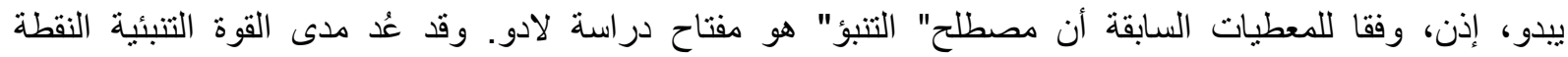

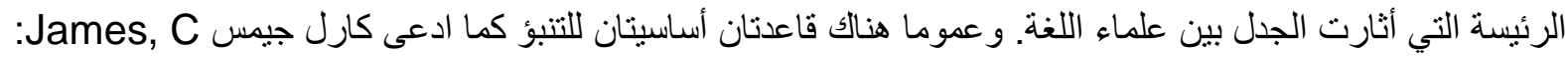
القاعدة الأولى تركز على إمكان التنبؤ باعتماد التعميم انطلاقا من الحالات المرصودة. وهو الاختبار الذي يمكن أن يتبناه من بعتمد مقاربة تحليل الأخطاء. 
القاعدة الثانية تستند إلى مبدأ أكثر طموحا يمكن عبره لأي أحد أن يتنبأ بإحدى الظواهر، على أساس رصد ظواهر

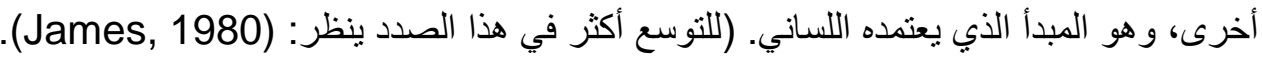

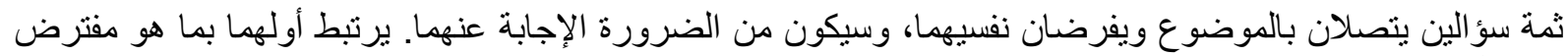

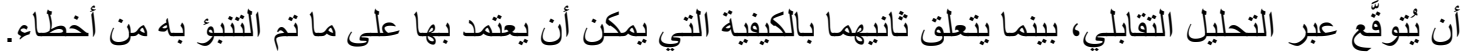

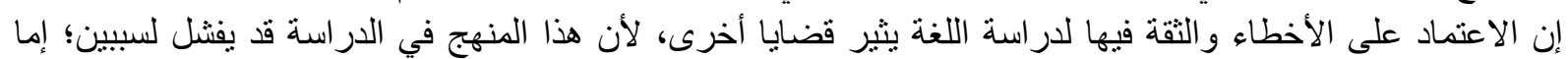

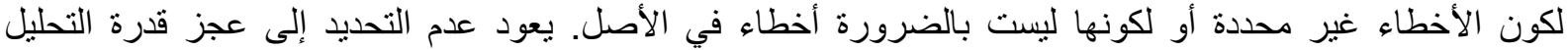

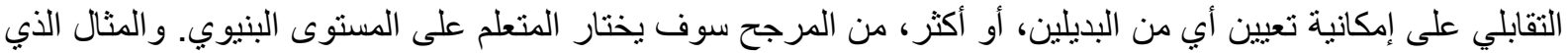

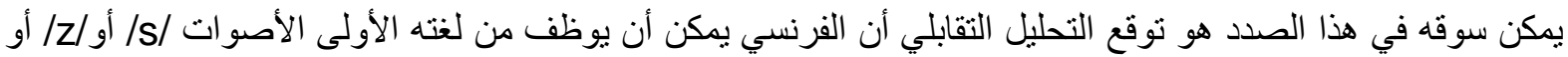

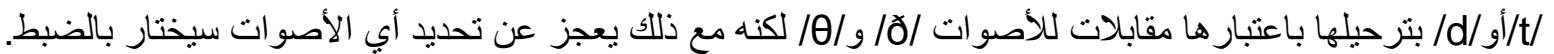

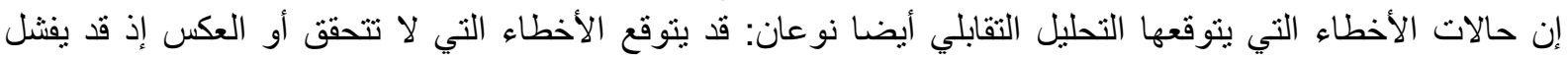
في توقع الأخطاء التي سترنكب. لقد منح عمل لادو (1957) و الكليات اللغوية، و عمل شومسكي دفعة قوية لفرضية التحليل التقابلي بشكل يجعل طرحها

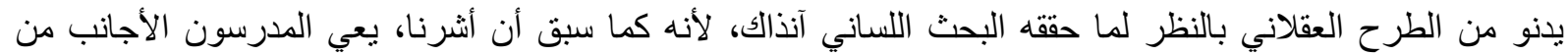

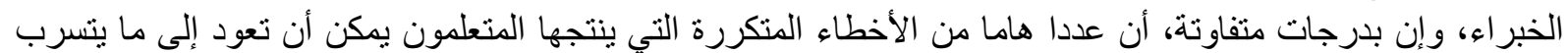
من أنماط اللغات الأولى إلى اللغات الأجنبية.

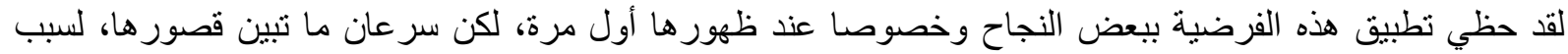

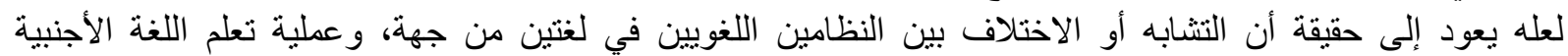

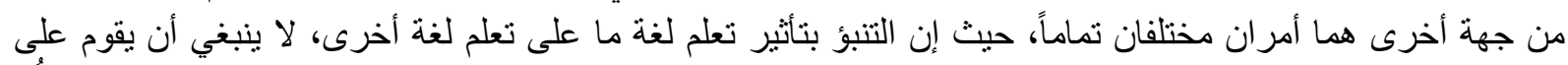

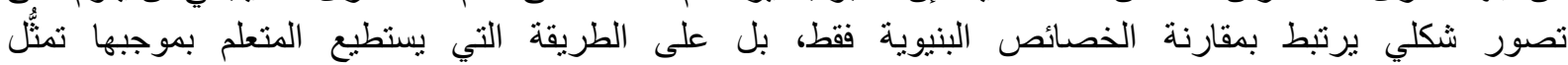
هذه الخصائص وتحققها ثم تعلمها. عموما، أسهم منهج التحليل التقابلي في تصنيف لغات العالفيات العالم المختلفة إلى عائلات لغوية متعددة، وقد كان من أهم

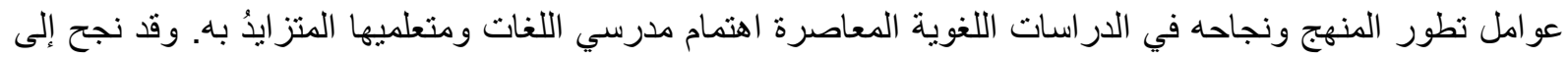

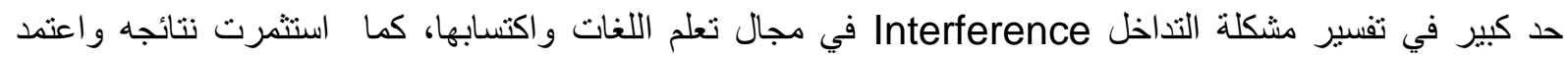
تطبيقها بشكل واضح قصد نطير تطوير مناهج طرق تعليم اللغات الأجنبية. فرضية تحليل الأخطاء اللغوية

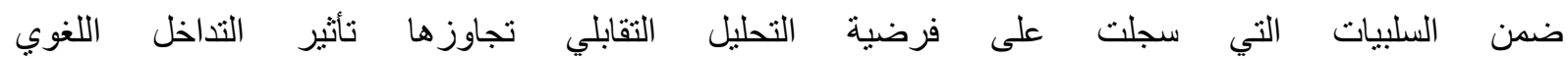

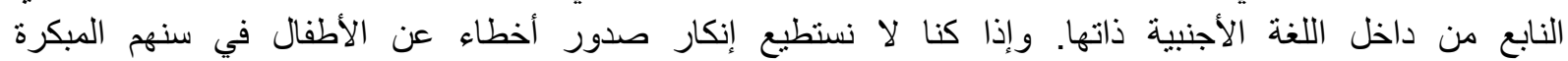
عند استخدامهم اللغة الأولى لأسباب عدة مردها التطبيق الخاطئ للقواعد اللغوية المتعلمة مسبقا، فإن الأمر نفسه قد برد الإن عند تعلم اللغة الأجنبية. تجدد الاهتمام بتحليل الأخطاء اللغوية Linguistics Error Analysis مع مقاربة التحليل التقابلي التي دعوت إلى التى

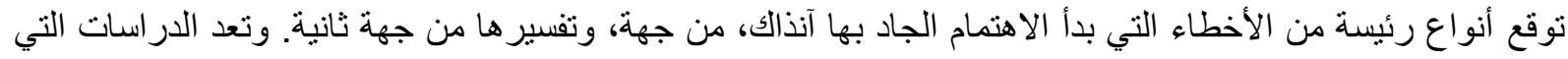

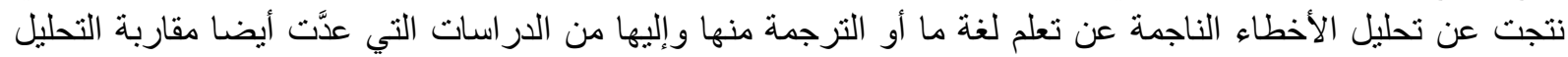

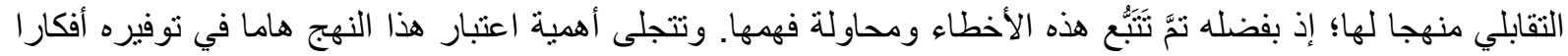

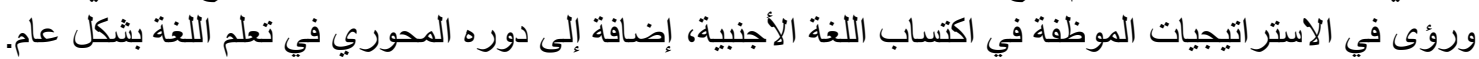

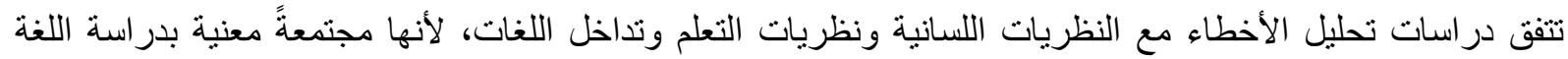

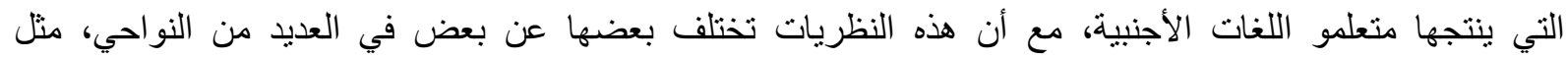
الافتر اضات النظرية و المنهجية و الرؤية المقدمة بشأن طبيعة تعلم اللغة الأجنبية.

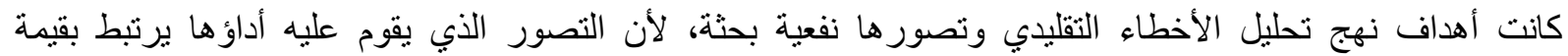

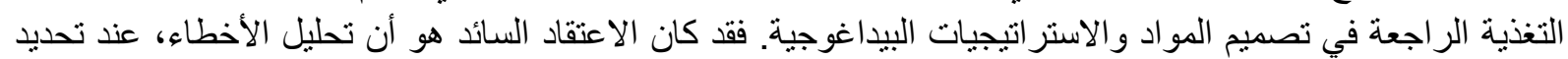

مجالات الصعوبة بالنسبة للمتعلم قد يساعد في:

تحديد تسلسل عرض العناصر المستهدفة في الكتب المدرسية والفصول الدراسية، بالتركيز تسلسليا على العناصر الصعبة

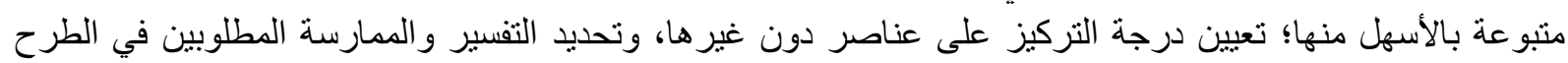
عبر مختلف العناصر في تعليم اللغات؛ وضع الدروس التقويمية والتمارين؛ تعريف العناصر لاختبار كفاءة المتعلم. 


\section{APPLIED LINGUISTIC APPROACH TO TEACHING FOREIGN \\ LANGUAGES THEORETICAL AND METHODOLOGICAL MODELS}

لذلك فإن التركيز على "تطبيق" هذا النهج في تحليل الخطإ واضح.

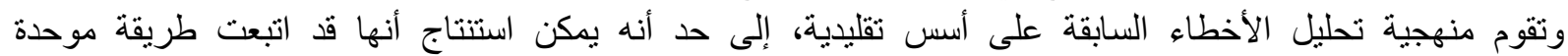
على الإطلاق، وتتحدد في اعتمادها الخطوات الآتية:

جمع البيانات إما من تكوين التمارين الحرة بتركيب المتعلمين لموضوع معين، أو باعتماد إجابات

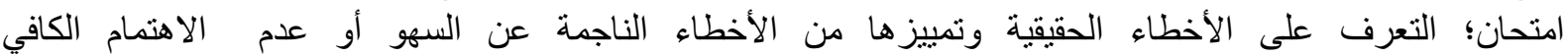

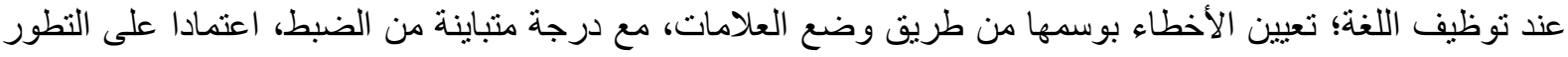
اللغوي الذي مورس في هذه المهمة، واحتر ام الطبيعة الدقيقة للانحر اف الذي حصل؛ على سبيل المثنال، عدم نوظيف حروف الجر، والتسلسل غير المضبوط للأزمنة، وما إلى ذلك؛ وصف الكان الأخطاء وتصنيفها إلى أنواع، ومنها المتعلقة بالمستويات الصوتية والنحوية والصرفية، أو المرتبطة بالاتساق؛ ومن ذللك على سبيل المثال أخطاء مطابقة الفعل للفاعل

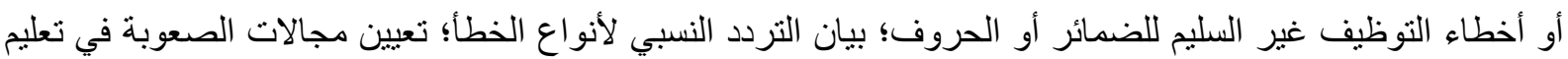

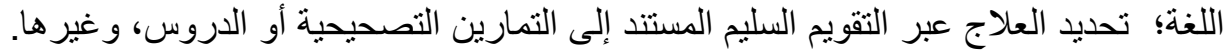

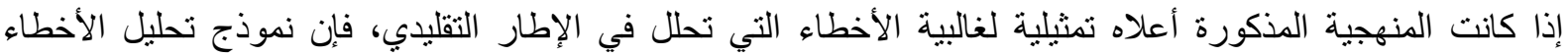

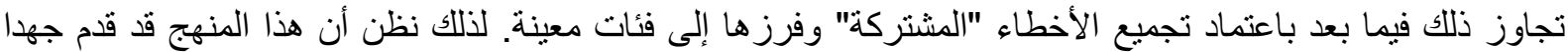
كبيرا من حيث تحديد "الخطأ" بطريقة بيداغوجية منتظمة وصارمة لكثف حدوث أخطاء على المستويين اللغوي أو الو النفسي.

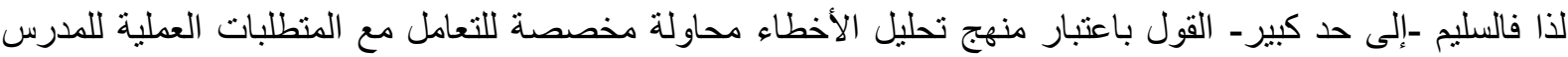
في الصف الدر اسي، وقد شملت الدر اسات المو الية للنهج التقليدي في تحليل الأخطاء ما يأتي:

تحليل مصدر، أو مصادر، الأخطاء. ومن ذلك على سبيل المثال، تدخل اللغة الأولى والتعميم ووجود التباينات في نظام تهجئة لغة التعلم مقارنة مع نظام اللغة او اللغات المتعلمة... الخ؛ تحديد درجة الاضطر ابات الناجمة عن الخطإ أو مدى الإى

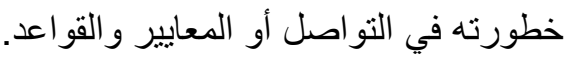
يسمح إدراج المهمتين المذكورنين من ملاحظة إمكانية جعل مجال تحليل الأخطاء ذا قاعدة عريضة لتطور نظرية الأخطاء. يملك تحليل الأخطاء في البدايات الأولى لاعتماده التحليل التقابلي جهازا نظريا منطورا نسبيا اعتبارا للمستوى الذي الذي التيات

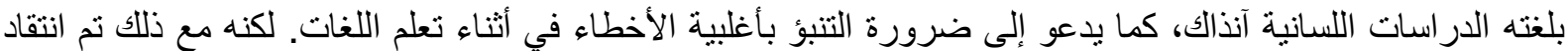

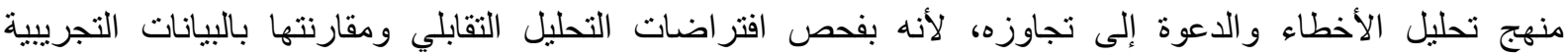

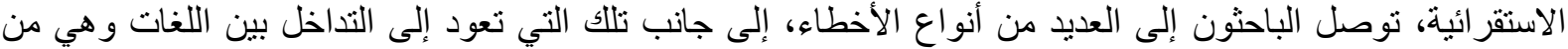

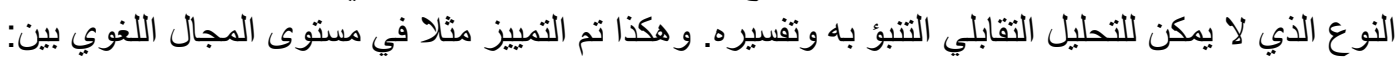

أـ الأخطاء داخل اللغة: ألفاء Intralingual Errors التي تعود إلى اللغة الهدف ذاتها، فتعكس الخلل الذي يقع فيه المتعلم أثناء تعلمه قو اعد اللغة الأجنبية، ومن ذلك التعميم أو عدم ضبط سياق التوظيف.

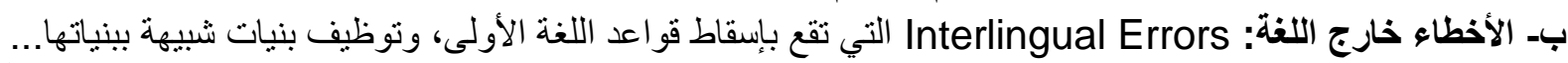

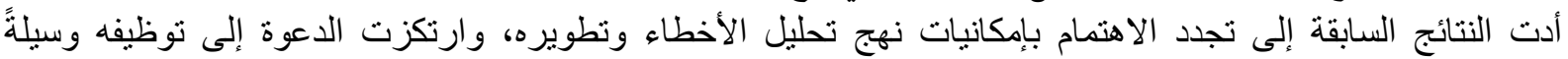

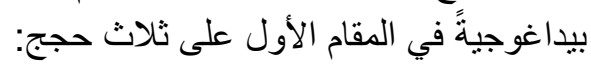

أولاها؛ لا تقتصر مقاربة تحليل الأخطاء على حصر الأخطاء الناجمة بسبب التداخل بين اللغات، كما هو شأن للتحليل التقابلي، بل إنه يسلط الضوء في كثير من الأحيان على تلألك التي ارتكبها المتعلمون؛ ومنها الأخطاء الناشئة عن أسباب

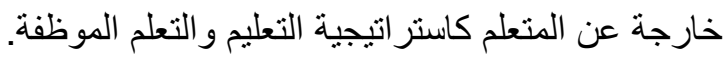

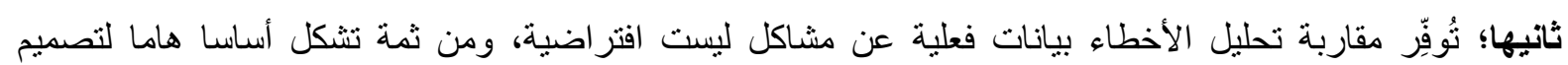
استر اتيجيات نربوية أكثر كفاءة و أكثر اقتصادا. ثالثها؛ لا يصطدم نهج تحليل الأخطاء مع المشاكل النظرية المعقدة التي واجهتها مقاربة التحليل التقابلي، ومن ذلك، على

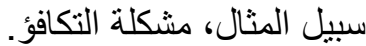


استتادا إلى مثل هذه الحجج، لا ضرورة لإعطاء الأولوية لمقارنة مسبقة مبنية على قواعد النحو، وبذللك يعتبر تحليل

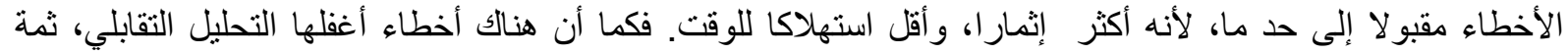

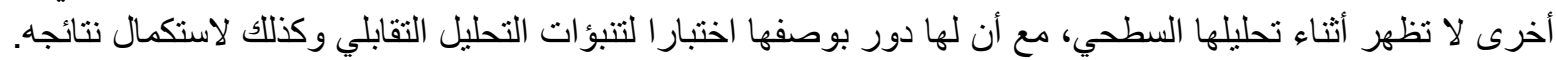

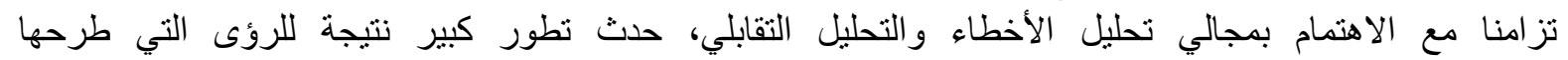

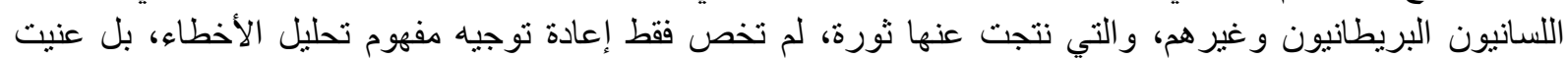

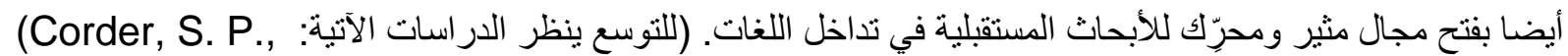
(Selinker, L., 1969, pp. ،(Selinker, L, (1971-b-)) ،(Strevens, P. S.) ،1967, pp. 161-170)

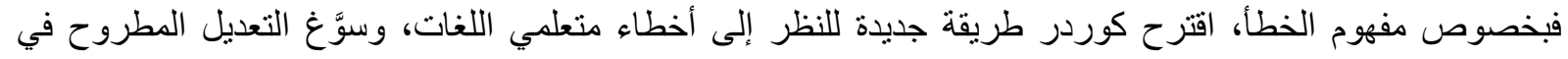
وجهات النظر على أساس أوجه الثبه الكبيرة بين الإستر اتيجيات التي يوظفها الأطفال أثناء تعلمهم لغتهم الأم، وتلكات التئي

يستخدمها متعلمو اللغة الأجنيية. إن مفهوم "خطأ" من وجهة نظره هو وظيفة من الوظائف التي تُعتمد في الممارسة التقليدية لتركيز وجهة نظر المعلم

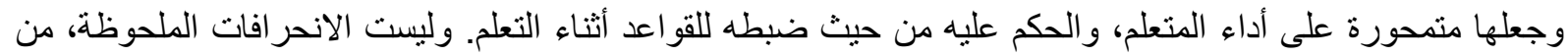

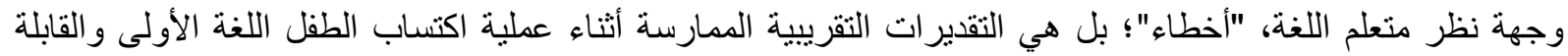

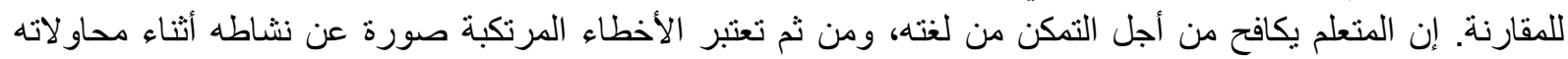

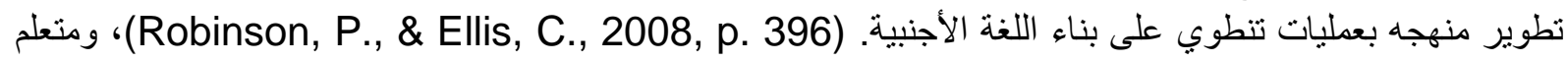

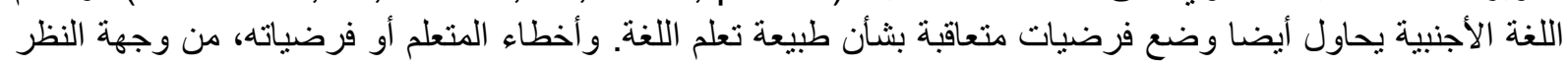

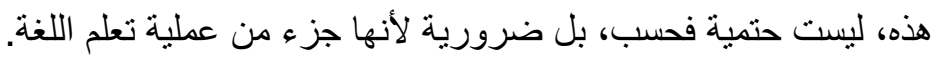

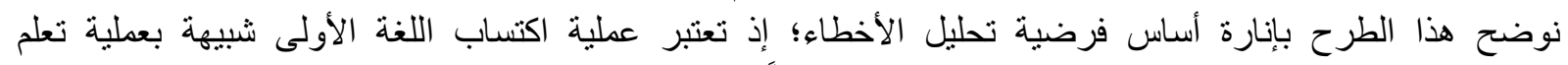

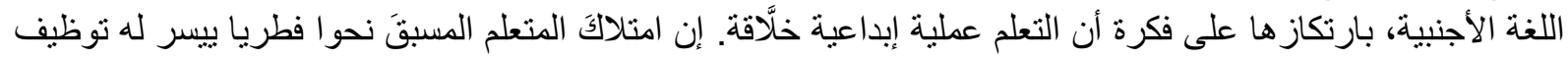

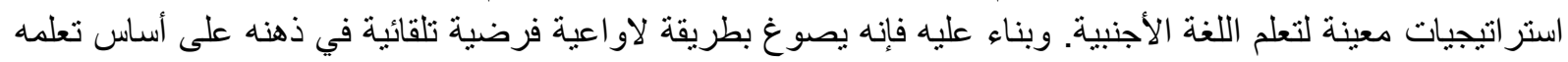

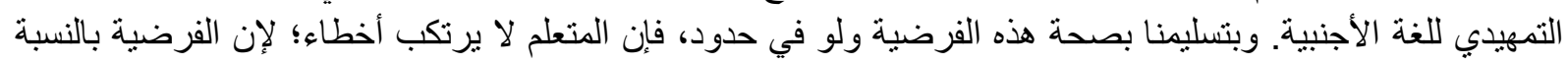

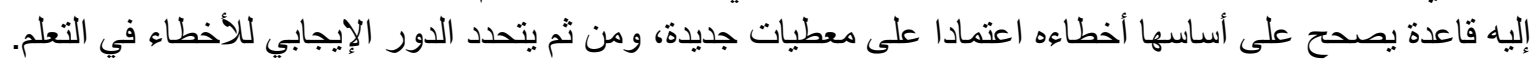

يميز كوردر بين نوعين من الأخطاء: الهفوات Mistakes، وهي الانحر افات الحاصلة نتيجة لظروف الإنجاز، ومنها، على سبيل المثال، قيود الذاكرة

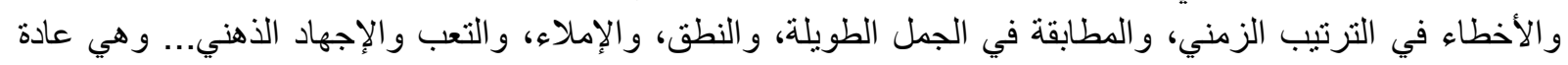

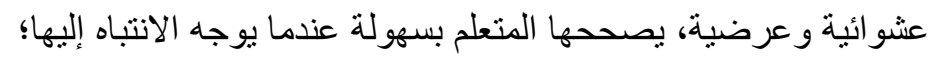

الأخطاء Errors، وهي الأخطاء النسقية المتعلقة بجهل المتعلم للقاعدة، مما ينتج عنه خرق للنظام اللغوي المميز للغة المعنيَّة في مرحلة مُعَيَّنة من التعلم. الأحطاء

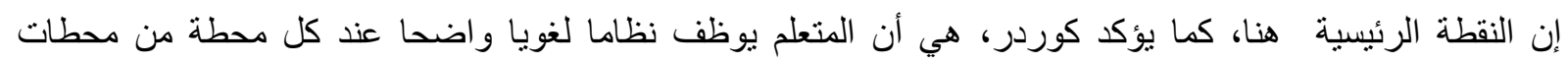

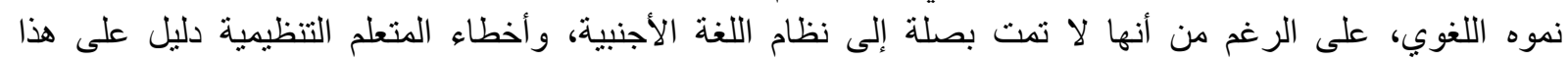

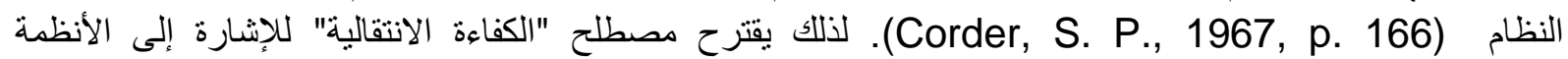
الوسبطة Intermediate systems التي يشيدها المتعلم أثناء عملية تعلم اللغة الأجنبية.

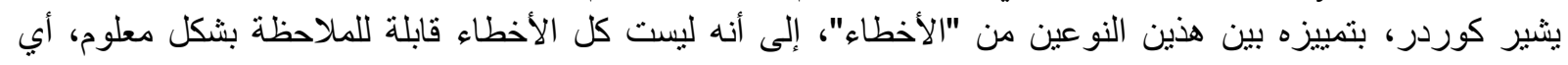

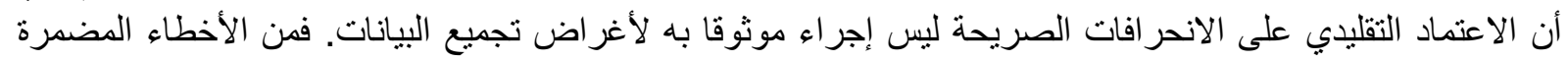

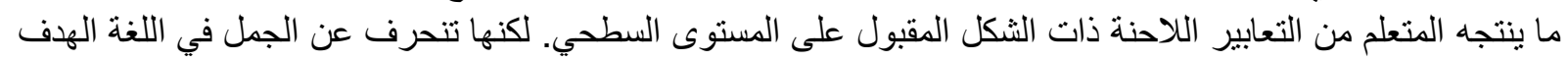

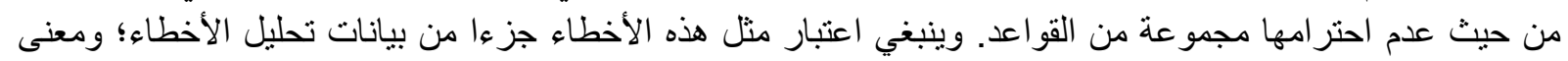

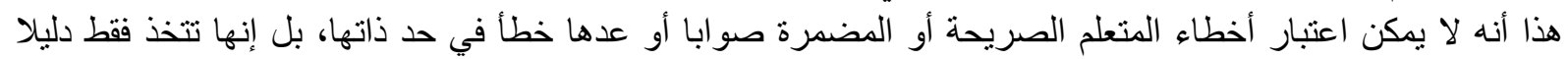

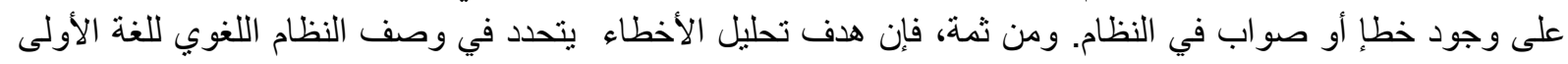

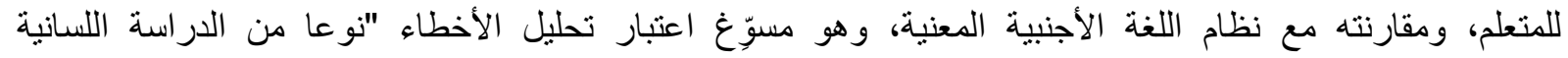

المقارنة". (Corder, S. P., 1973, p. 274). 


\section{APPLIED LINGUISTIC APPROACH TO TEACHING FOREIGN \\ LANGUAGES THEORETICAL AND METHODOLOGICAL MODELS}

ينبغي إذن، اعتمادا على ملاحظة كوردر، القيام بوصف النظام اللغوي للمتعلم، لأنه يعتبر عنصر ا حاسما، إذ يُمكِّن

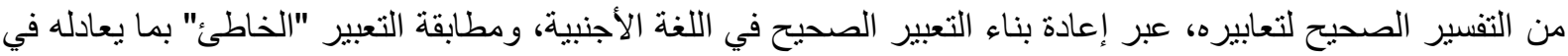

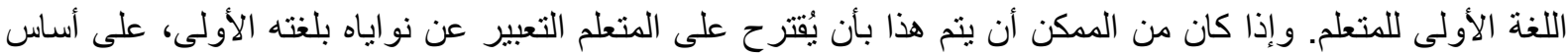
أن ترجمتها تضمن ملاءمنها، ثم بعد ذلك يعيد بناءها باللغة الهدف، فإنه إنهان بمكن أن تعد نتيجة هذا الإجر اء إعاء إعادة بناء مقبول،

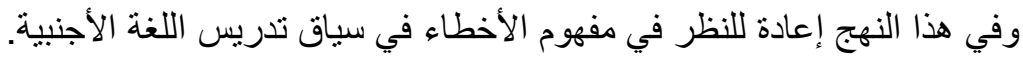
إن الأساس الذي يحق لنا استخلاصه من مقاربة تحليل الأخطاء، وفق الوارة الذارد في الدراسات السابقة، هو توسيعها لمفهوم

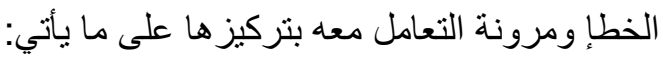

رصد معايير للتمييز بين الأخطاء المنهجية والأخطاء الإنتاجية الناجمة عن التعميمات الخاطئة و الفصل بينها لجعل التعلم

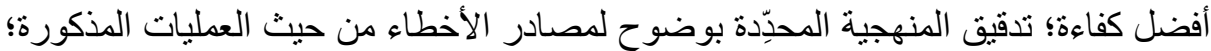

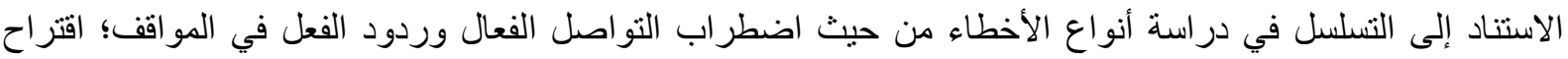
مفهوم "الخطأ" المرفوض في مقابل "الهفوات" المقبولة في سياقات تعلم اللغة الأجنبية؛ التمييز بين المفهومين في تقويم

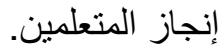
إن أخطاء متعلمي اللغة الأجنبية النانشئة عن تدخل لغتهم الأولنتعا لهذا ليست إلا حالات تكييف الطفل، إذا كان يلجأ

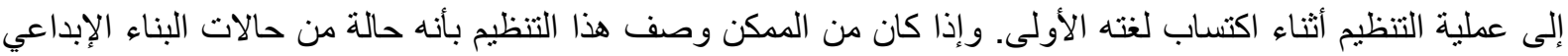

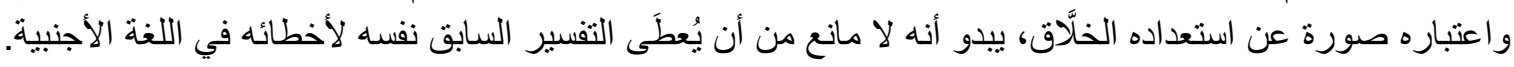

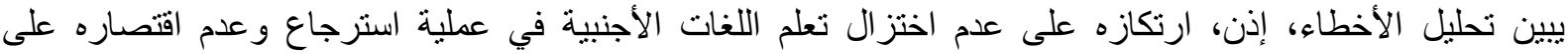

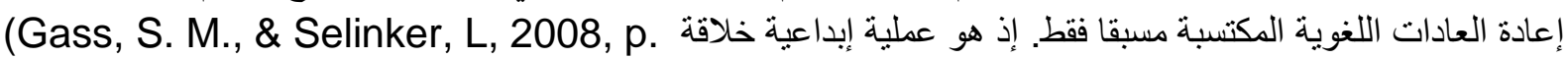

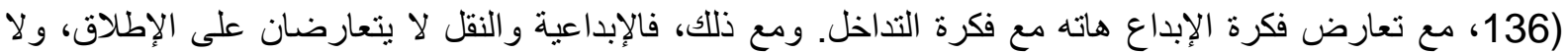

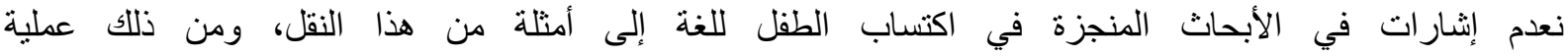
التعميم Overgeneralization التي تفرض تدخلها بقوة؛ إذ يلجـأ إليها الطفل باعنبار ها الإستر اتيجية الوحيدة الأكثر أهمية في تعلم اللغة.

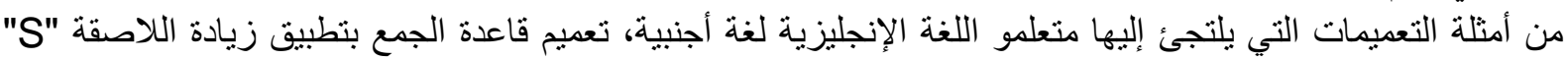
على كل الكلمات دون الأخذ بعين الاعتبار الحالات الاستثنائية، فيكتب بطريقة الآلية الآنة:

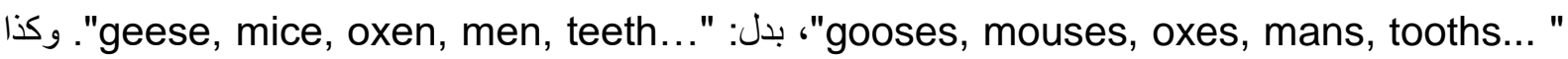
تعميم قاعدة إضافة اللاصقة "er " على كل كلمة لصياغة اسم التفضيل من قبيل: ( tall: taller, large: less:little, further:far, lgood...) و الحال أن هنالك كلمات لا تنتظم لهذه القاعدة ومنها: larger... better:well .

يستنتج من هذا أنه لا يفترض إلغاء التحليل التقابلي نهائيا، لإن هناك حاجة ماسة إلى بحوث أكثر صرامة لتحديد

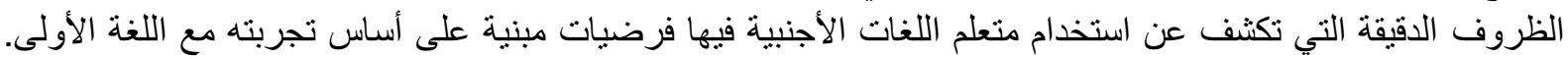

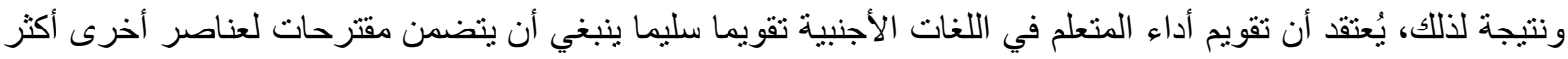
فعالية دون إلغاء جانب التداخل بين اللغات.

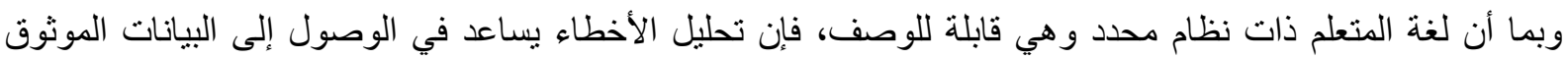
بها، التي يمكن أن تكثف أن التداخل بين اللغات يحصل بسبب معرفة المتعلم الأساسية بلغته. وتكون لنتيجة نهج التهات التحليل

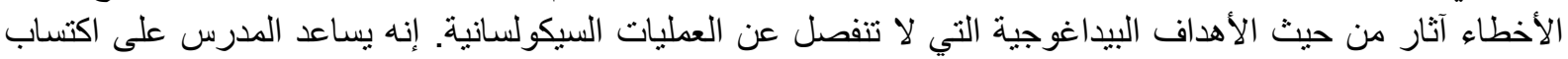

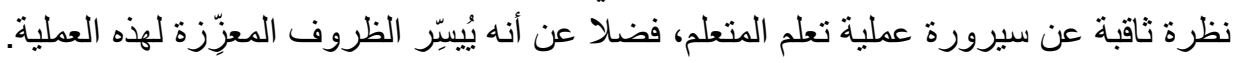

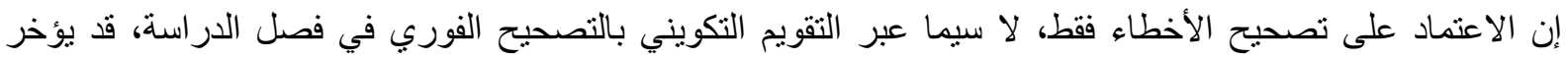

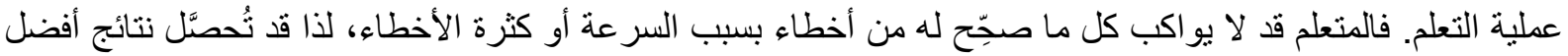

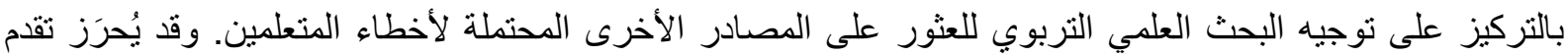

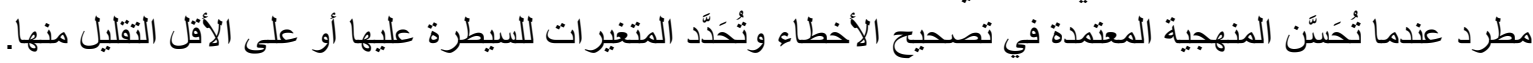


عرض سلينكر فرضية تداخل اللغات Interlanguage(s) Hypothesis سنة 1972 مشيرا بها إلى تميز الكلام

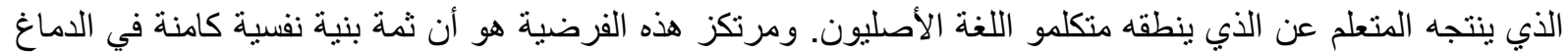

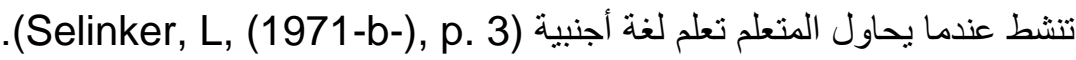

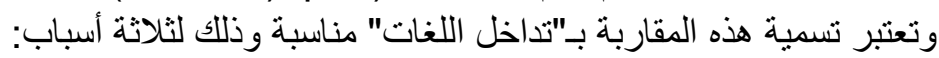

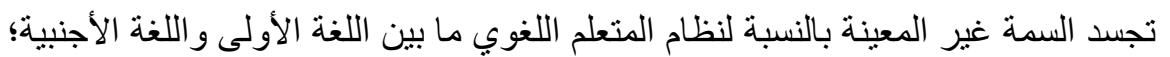
تمثل السر عة الاستثنائية و الدينامية التي بموجبها يحصل التئية التغير عند متعلم اللغة؛

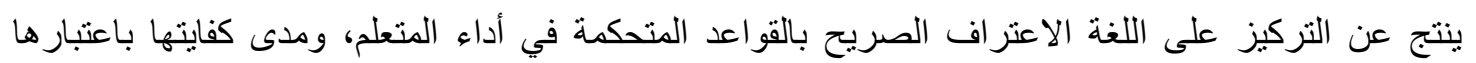
نظاما تو اصليا وظيفيا. تكثف هذه المقاربة عن نظام لغوي مستقل يمكن ملاحظته عند المتعلمين الذين يحاولون إنتاج لغة أجنبية. ومن ثم ثمان

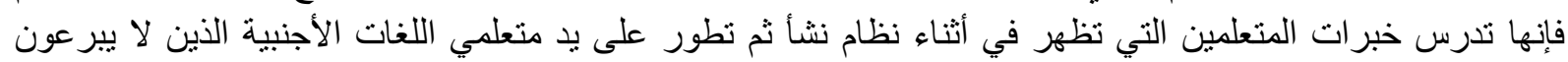

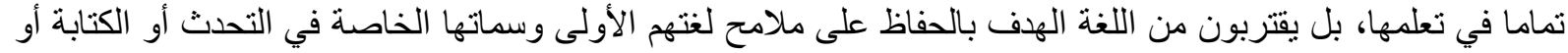

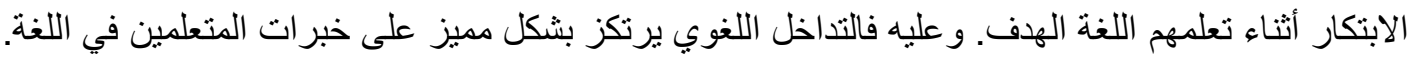

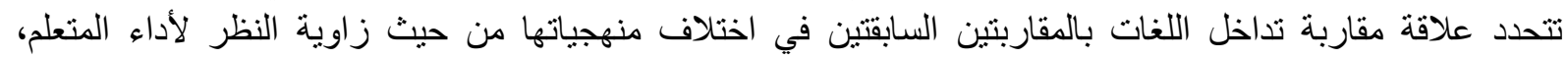

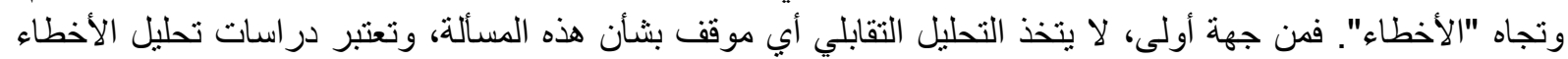

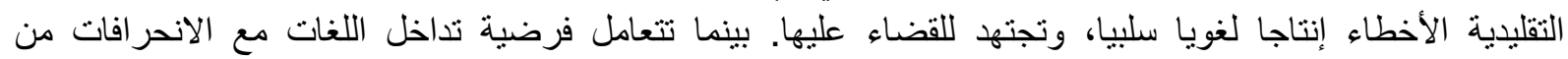

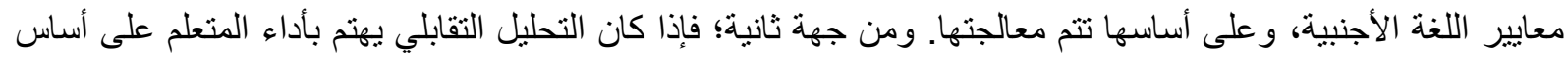

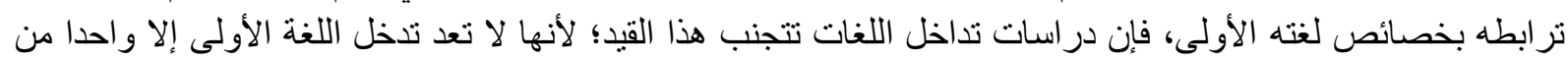

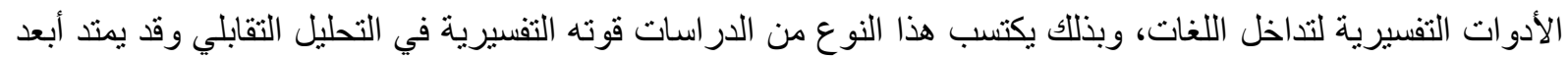
من ذلك. من الناحية المنهجية، يمكن القول إن دراسات تداخل اللغات تميل إلى إدراج كل الافتراضات التي ينبني عليها الإليا التحليل

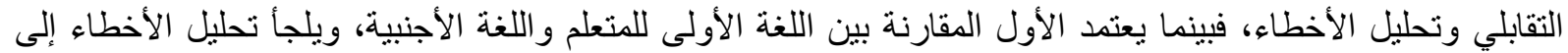

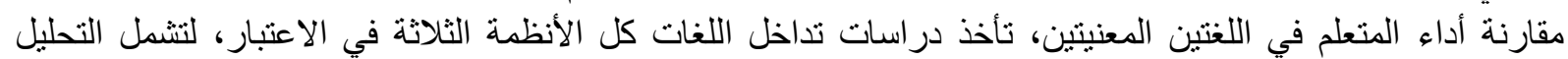

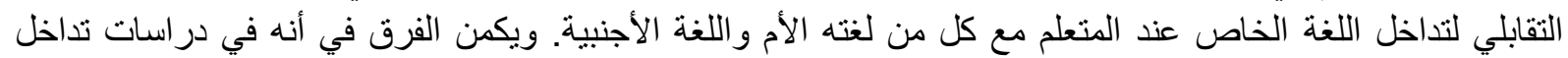

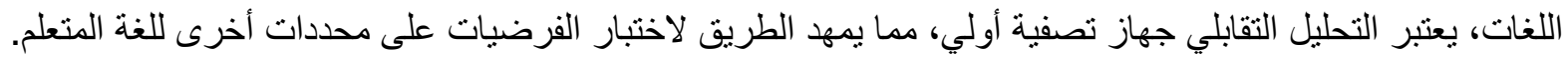

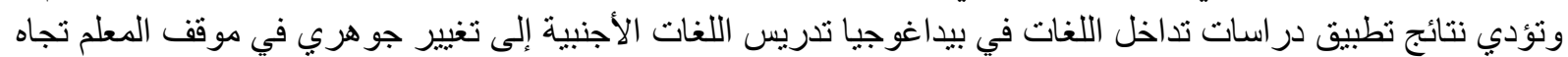

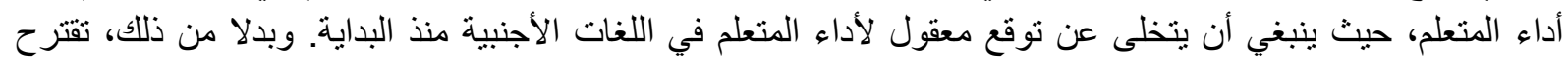

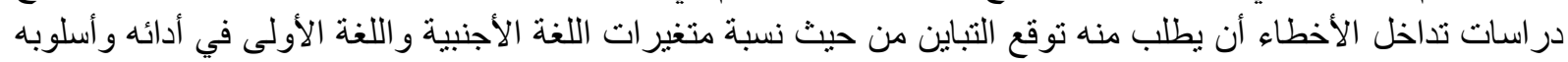

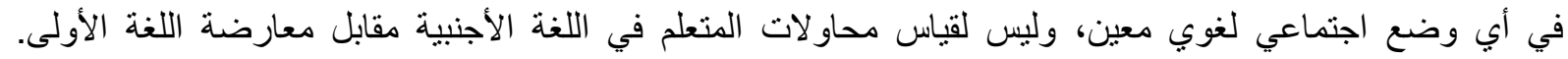

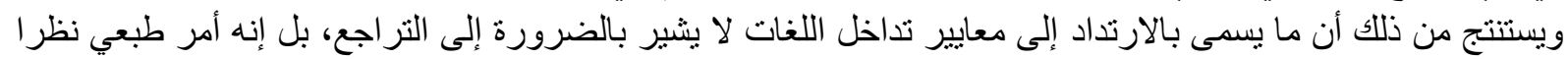

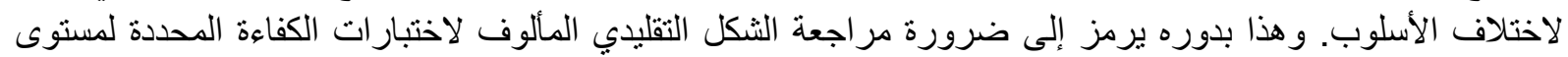

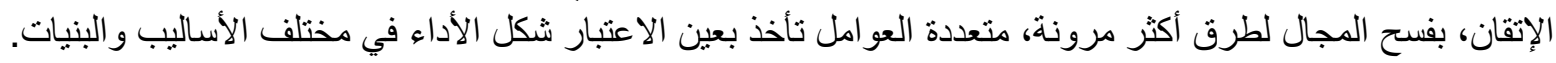

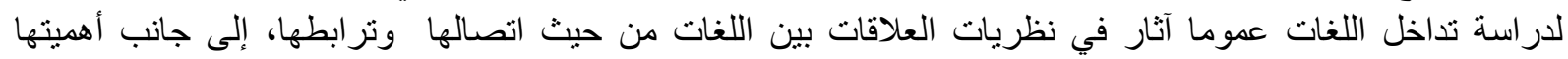

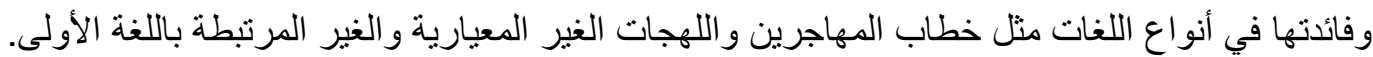

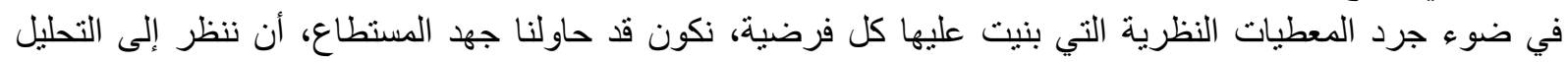

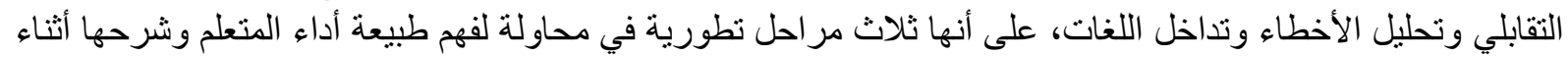

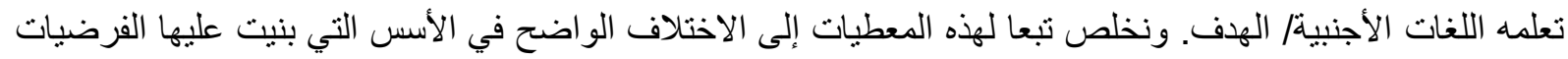

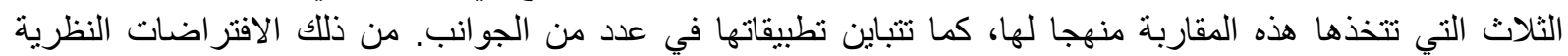

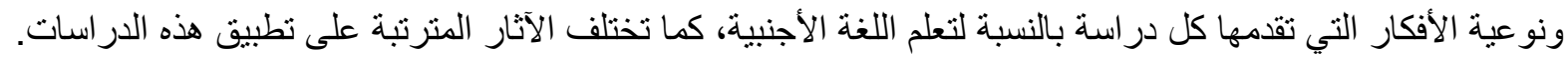

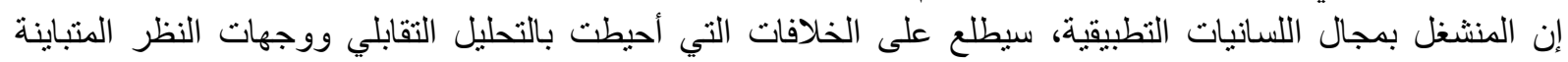

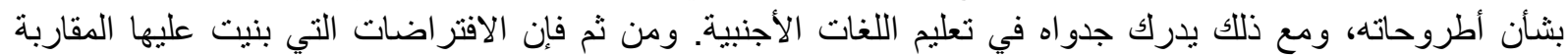

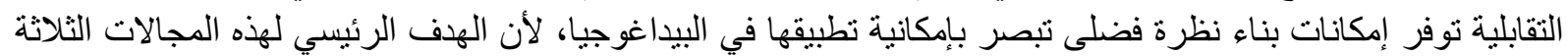




\section{APPLIED LINGUISTIC APPROACH TO TEACHING FOREIGN \\ LANGUAGES THEORETICAL AND METHODOLOGICAL MODELS}

هو تيسير تعلم اللغة الأجنبية بالوقوف على نظرة عميقة لطبيعة أداء المتعلم؛ إذ إنها تشكل أداة فعالة تمكن من امتلاك فكرة عن بعض أسباب صعوبات التعلم، و لأنها تجسد نطور بال بارز الفي الدر اسات اللسانية في إطار التداخل بين اللغات.

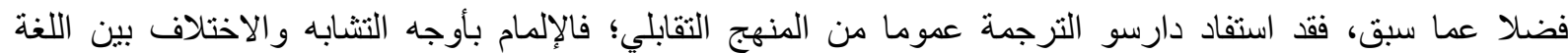
الأولى و اللغة الأجنيية يجعل المترجم في منأى عن ارتكاب أخطاء كثيرة من قبيل الترجمة الحرفية للتر اكيب و الدلالات. لذللك نرى أهمية الاستفادة من القضايا التي استجدت مع هذه المقاربة ولئ وبخاصة على على مستوى اللخات المنتمية إلى عائلات

مختلفة

المقاربات اللاتقابلية

ركزت المقاربات اللاتقابلية The Non-Contrastive Approach انتقاداتها الرئيسة للمقاربة التقابلية على نقطتين:

أولاهما الانتقادات الموجهة إلى التوقعات التي بنيت عليها المقاربة التقابلية.

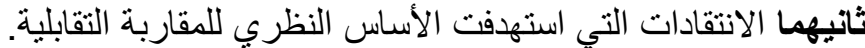

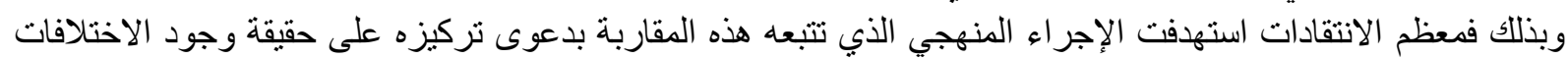

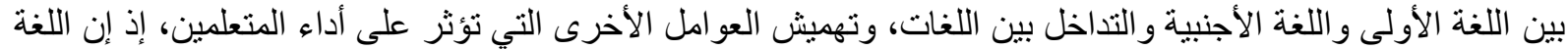

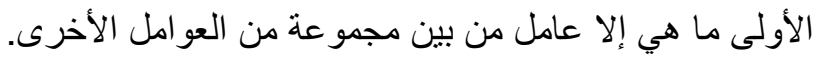

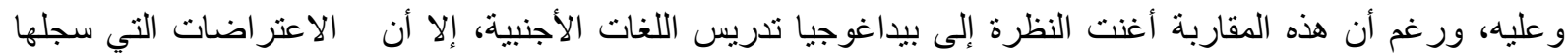

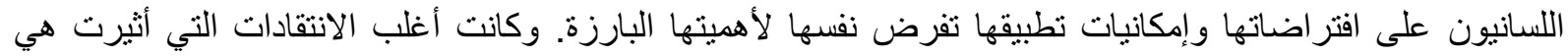

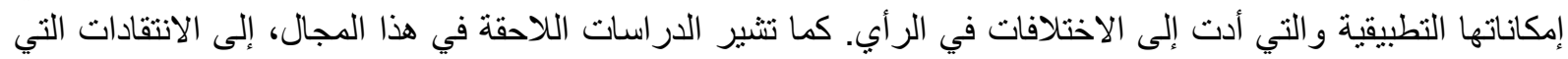

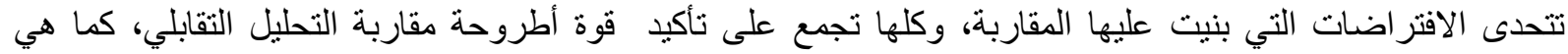

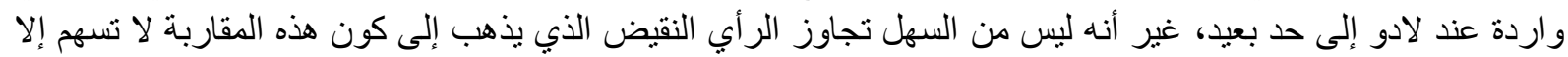

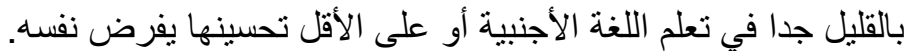

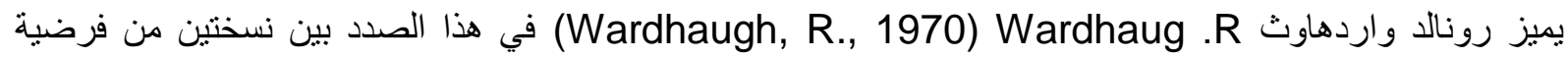
التحليل التقابلي؛ الأولى نسخة قوية و الثانية ضعيفة. ومع استناد النسختين معا إلى فرضية تدخل اللئل اللغة الأولى في تعلم اللغة

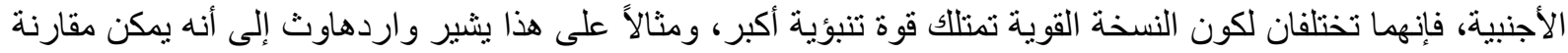

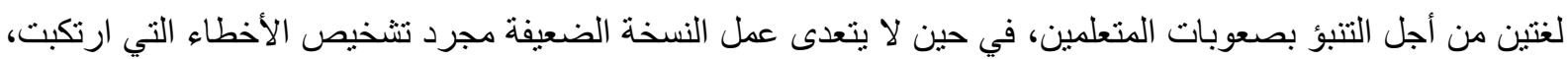

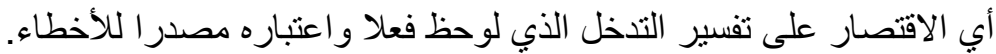

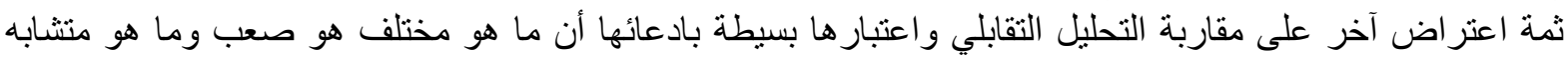

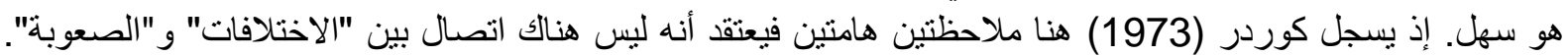

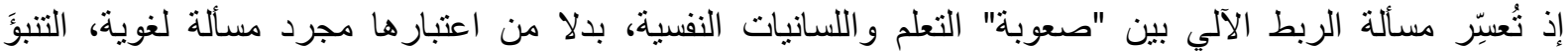

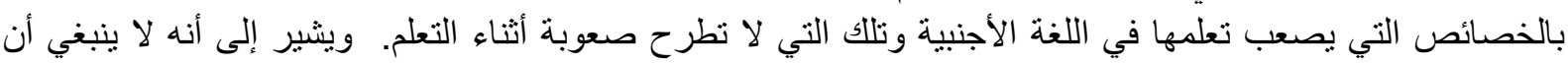
يقتصر المتعلمون على تعلم الاختلافات بين اللغة الأولى واللغة الأجنبية فقط، بل ينبغي أيضا اكتشاف أوجه التهائ التشابه بينهما.

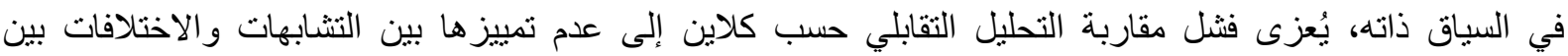
النظامين اللسانيين من جهة و التحليل اللساني للإنتاج والفهم الحقيقيين من جهة أخرى. . Wolfgang, K, 1989, p.

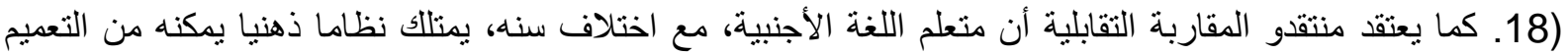

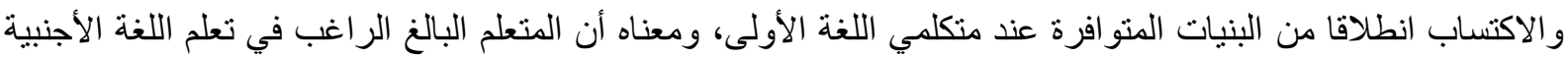

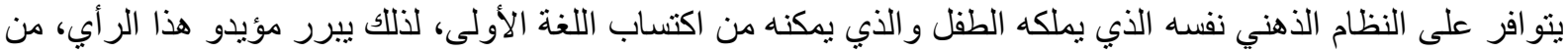

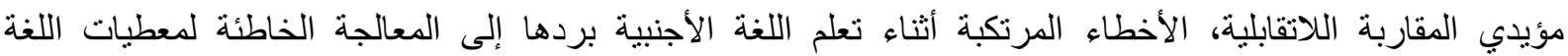
| (الاجنبية.

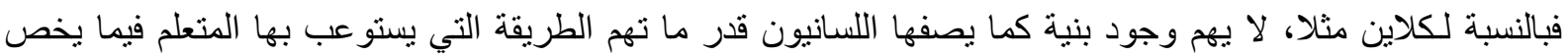

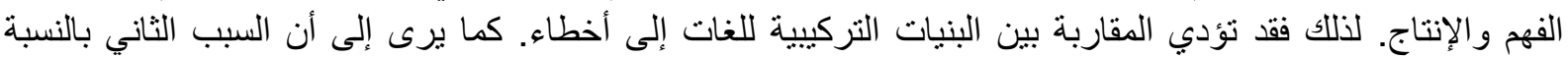

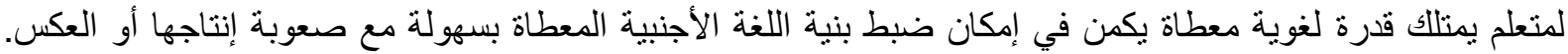

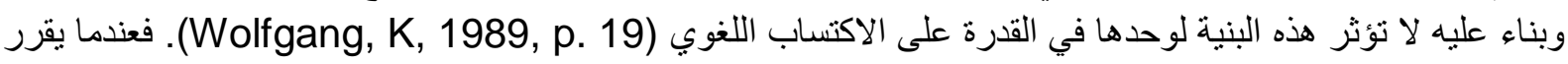

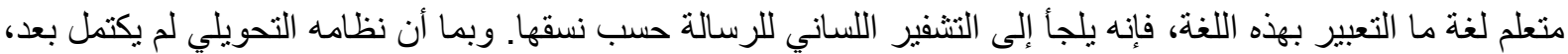

يستعمل أحيانا القو اعد الخاصة بلغته الأولى لسد الفراغات التي تنقصه، و هو ما يتحقق على المستويات اللغوية جميعها. 
يعتقد كلاين أيضا أن المتعلم أثناء عملية تعلم اللغة الأجنبية يحاول توظيف جميع إمكاناته المعرفية أثناء إنتاج معطيات

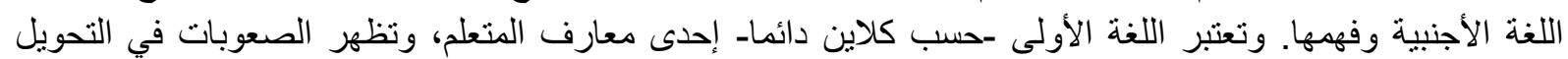

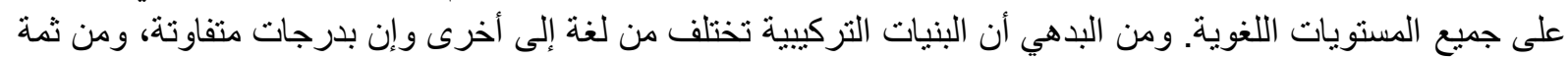

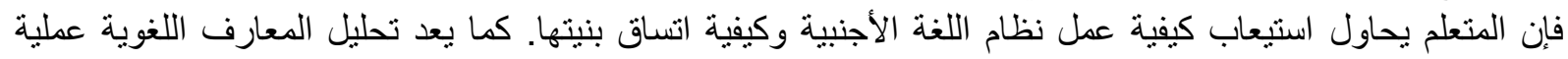

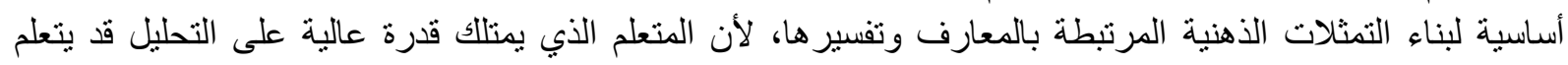
بشكل أفضل من المتعلم الذي لا يمتلكهاء

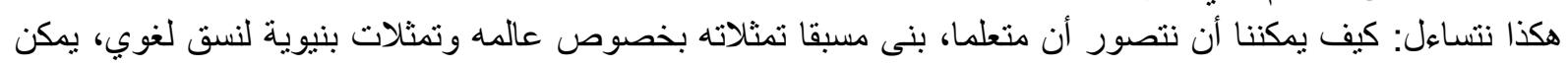

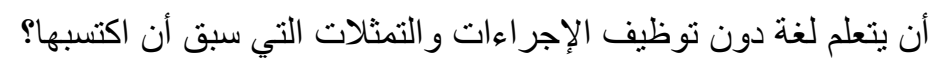

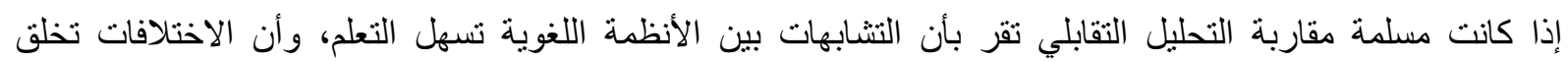

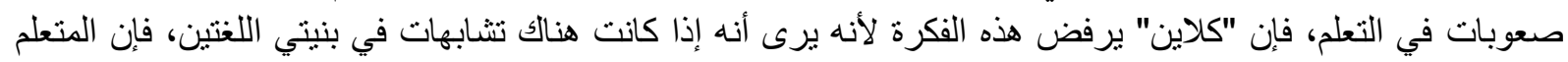

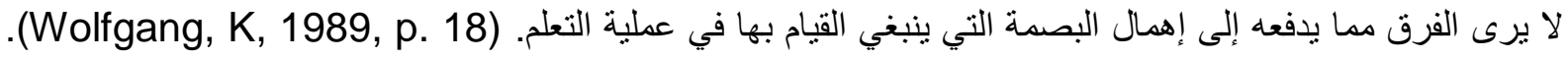

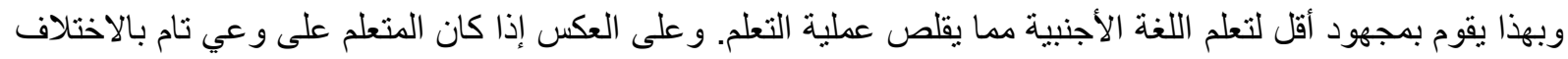

بين اللغتين، فإن هذا يدفعه إلى اكتساب أفضل للمعطيات المختلفة تماما على مستوى التركي التيبي أو الصواني التي للغة الأم.

\section{فرضية الجهاز الموجه}

إذا كانت النظريات السابقة قد اهتمت بالعلاقة بين اكتساب اللغة الأولى وتعلم اللغة الأجنبية، فإن كر اشن بنشغل ينشغل

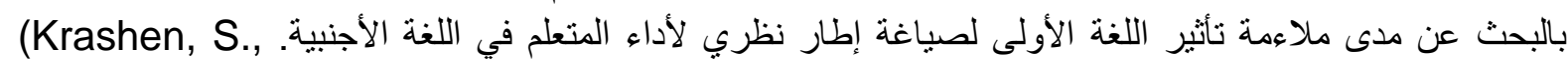
Spada \& ون 1981, p. 68) Lightbown (Spada, N., \& Lightbown, P, M., 2002)

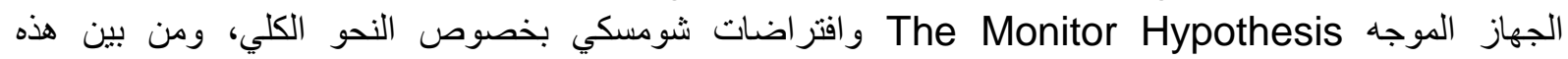
الافتراضات اعتبار الكائن البشري يكتسب اللغة دون تعلمٍ أو تغذيةٍ راجعة مرتبطة باللغة الأولى أو اعتمادٍ على تصحيح الأخطاء. - افترات

ينطلق كر اشن من افتراض عمليتين مختلفتين جذريا يميز هما بـ "اكتساب اللغة الثنانية" و "تعلم اللغة الثانية". وهو بذللك

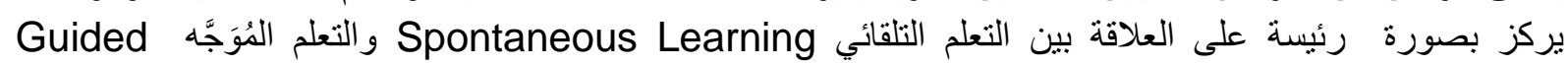
learning و وعلى أساس هذا الاقتر اض النظري فلان هنأك طريقتان لتعلم اللفة الأجنبية:

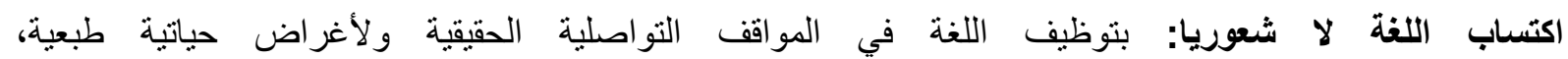

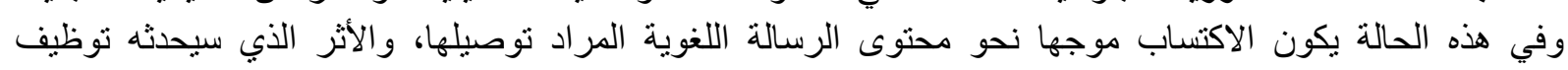

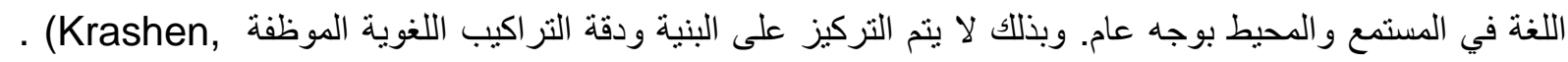
المنئ 1082, p. 10 وبموجب هذه الطريقة يكون التعلم عملية لا و اعية تتطابق فيها الطرق المهمة جميعها مع عملية استفادة

$$
\text { المتعلمين من اكتساب لغتهم الأولى. }
$$

تعلم اللفة إراديا: بالتمكن من القواعد اللغوية للغة الأجنبية دون الاهنمام بالتواصل اللغوي المباثر، إذ يكون

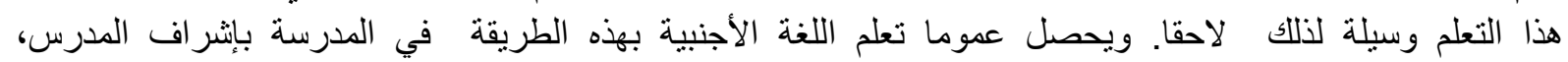
ويتأثر بعمليتي التوجيه و الضبط المحددين في الجهد الذي يبذله المتعلم لضبط لغة التعلم وتصحيح أخطائه كلما لزم ذللك. (Krashen, 1982, p. 11) إن أساس فرضية الجهاز الموجه هو تمييز كراشن بين الاكتساب والتعلم مع التأكيد على أن متعلمي اللغات الأجنبية

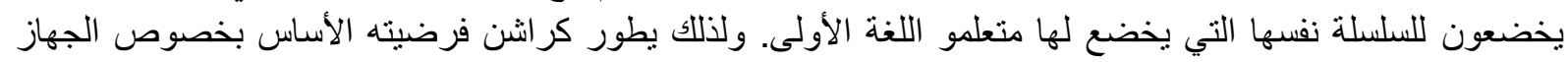

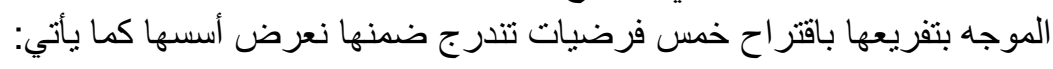

$$
\text { فرضية الاكتساب - التعلم }
$$

تقر فرضية الاكتساب - التعلم The acquisition- Learning Hypothesis أنَّ الكائن البشري يعمل بطريقتين

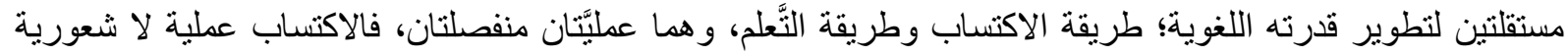

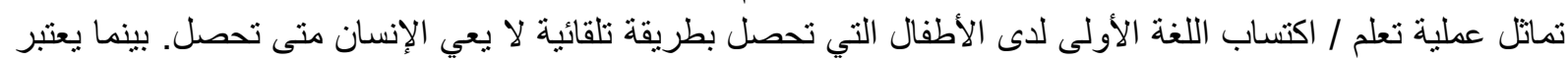




\section{APPLIED LINGUISTIC APPROACH TO TEACHING FOREIGN \\ LANGUAGES THEORETICAL AND METHODOLOGICAL MODELS}

تعلم اللغات عملية واعية، (Krashen, 1982, p. 10)، تحصل عادة في المدارس وتتم الاستفادة من الأخطاء المرتكبة لأن تصحيحها من المدرس أو أب موجه آخر يجعل المتعلم يغير وعيه بالقو اعد و إدر اكه لها، ومن ثم تنتج عنها

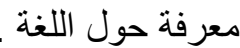

ومفاد هذا بعبارة أخرى أن الاكتساب يحصل بالتفاعل الطبعي مع اللغة عبر توظيفها في مواقف نواصلية و اقعية تؤدي

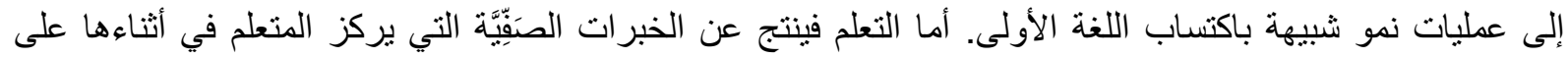

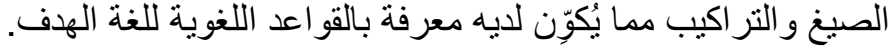

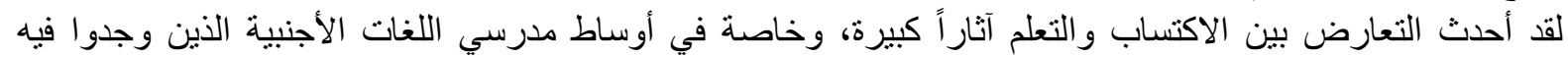

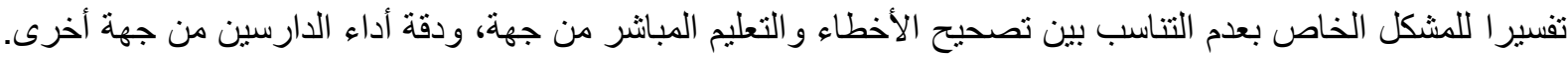
فلو كانت هناك آلية داخلية مسؤولة عن تقدم المتعلمين لأمكنها أن تفسر سبب عجز بعض الفئ المتعلمين في أثناء تواصلهم عن

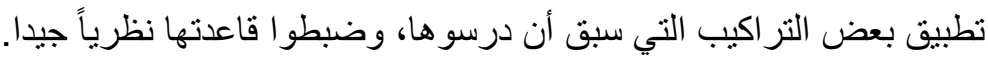
فرضية التدرج الطبعي

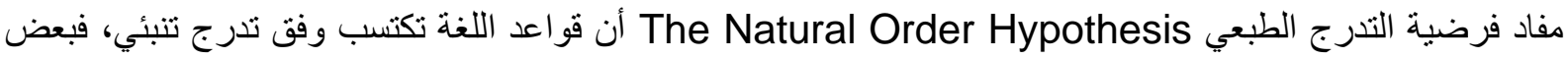
القو اعد تُحرز مبكر ا بينما يتأخر اكتساب البعض الآخر إلى وقت لاحق. بمعنى أنه يمكن التنبؤ بأي مستوى من المسنويات

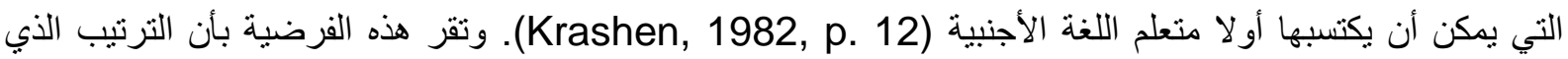
يخضع له اكتساب اللغة الأولى هو عينه الذي يُطوَّع له تعلم اللغة الأجنبية مع اعتبار مدى تعرض المنتعلم للغنة المعنبة في محيطه. يعتبر كر اثن اللغة الإنجليزية أكثر ملاءمة لنطبيق فرضية نظام التدرج الطبعي خصوصا على مستوى البنيات الصرفية.

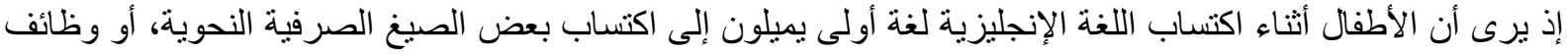

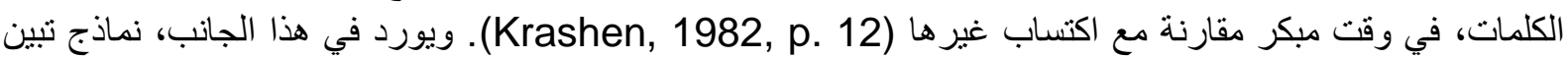
احتر ام التدرج الطبعي أنثاء تعلم إلحاق اللواصق Suffixes بالكلمات، فاللاصقة (ing) الدالة على التدريج كما في المثال الأتي:

5- He is playing football

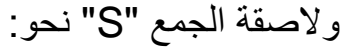

6-Two boys

تعتبران معا من بين الصيغ الصرفية المكتسبة أوليا، بينما يلاحظ تأخر اكتساب اللاصقة الدالة على المفرد الغائب S" The third person singular maker" ولاصقة التملك "S"S" كما في المثالين على التو الي:

7- He lives in London 8- Jonh's book. إذ لا يتم عادة ضبطهما إلا في وقت لاحت الاحق. ومن ثم فان صعوبات اكتساب هذا النوع من اللواصق لها علاقة بالتدرج الذي يتبع أثناء الاكتساب (Krashen, 1982, p. 12).

فرضية الجهاز الموجه

يرى كراشن أن مصطلحي "التعلم" و"الاكتساب" يوظفان بطرق خاصة بخصوص تعلم اللغة الأجنبية. وتقر فرضية الجهاز الموجه أن وظيفة الاكتساب تتحدد في إنشاء عبار ات المتعلم أولا، بينما تتعين وظيفة التعلم في كونه موَجِّها

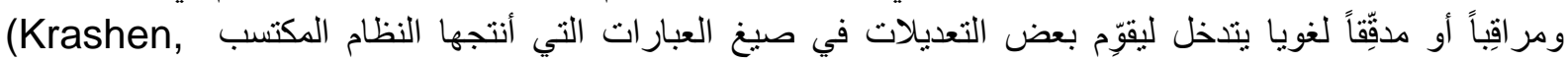
(1982, p. 15. ولذا فإن وظيفة الموجه هي تعديل المخرجات الصادرة عن النظام المكتسب قبل أن تتتج العبارة بصورة مكتوبة أو مسمو عة. و وليه تعد هذه الفرضية محاولة شرح كيفية تحقق عمليتي الاكتساب و التعلم، إذ تنتج اللغة عادة بتوظيف مكتسباتنا وقدر اتتا اللغوية. وبذللك فالوعي بالتعلم يشتغل جهاز اللمسح

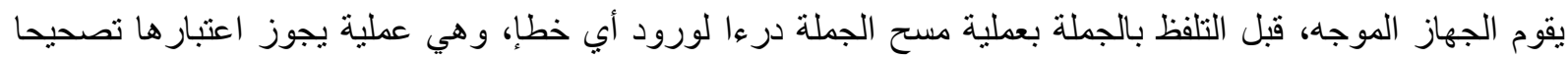


ومن الواضح أن عمل الجهاز ليس دائما، لذا يرى كراشن أن ثمة ثلاثة شروط ضرورية لتحقق عملية المسح بنجاح، وهي:

أن يكون المتعلم على دراية بالقو اعد مدركا إياها، لأن جهلها يعوق اشتخال الجهاز ؛

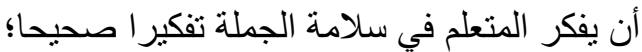
أن يكون لايه وقت من أجل التفكير واستخدام القو اعد بشكل فعال. (Krashen, 1982, p. 16). فرضية المدخلات

تتصور فرضية المدخلات The Input Hypothesis أن تعلم اللغة بصفة عامة يتم بطريقة واحدة؛ إما بفهم الرسائل أو عبر مدخلات مفهومة. وتحاول تفسير كيفية حدوث اللغة للمتعلم، وتعكس وجهة النظر القائلة إن تعلم اللغة الأجنيية،

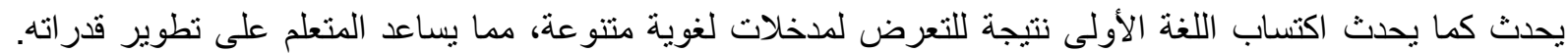

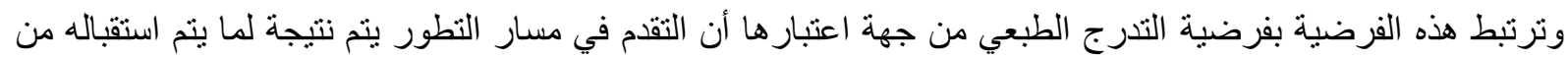
مدخلات مفهومة Comprehensible input، ونعني بها مدخلات اللغة الأجنبية التي تلي مباثرة مستوى القدرات

المتحقق عند المتعلم مسبقا من حيث درجة صعوبتها التركيبية. (Krashen, 1982, pp. 20-21). يعتبر كر اشن فرضية المدخلات جوهرية في نموذجه النظري لاكتساب اللغة الأجنبية (Krashen, 1982, p. 79)،

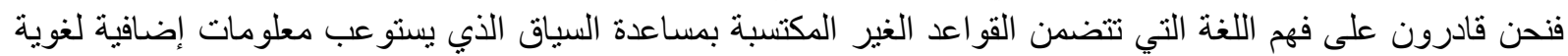

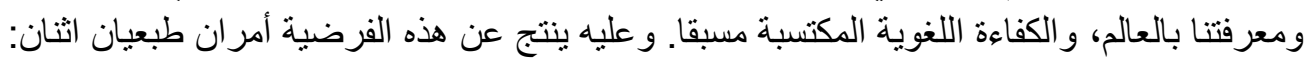

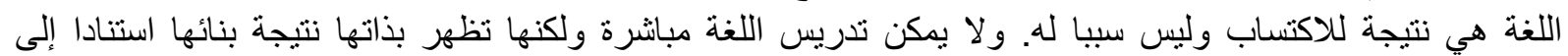

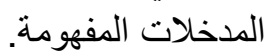

إذا كانت المدخلات مفهومة وكافية، فإن القو اعد اللازمة حينئذ ستتو افر تلقائيا. ولا يحتاج معلم اللغة لأن يتعمد تدريس

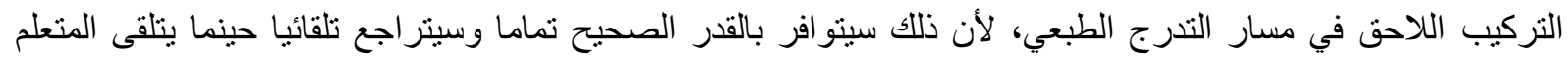

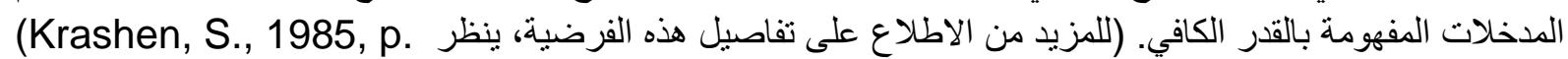
(Krashen, S. , 3003, pp. 15-30) و (80)

\section{فرضية المصفاة الوجدانية}

إن المدخلات المفهومة أساسية للتعلم، لكنها ليست كافية لتحقق ذلك، لأن المتعلم يحتاج أن يكون منفتحا عليها، و عليه فإن المصفاة الوجدانية هي عملية عرقلة ذهنية تحول دون توظيف المتعلم للمدخلات المفهومة الني استقبلها توظيفا تاما لتعلم اللغات (Krashen, S., 1985, p. 81).

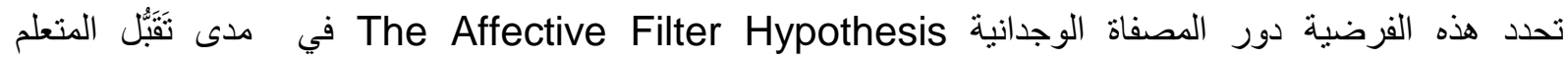

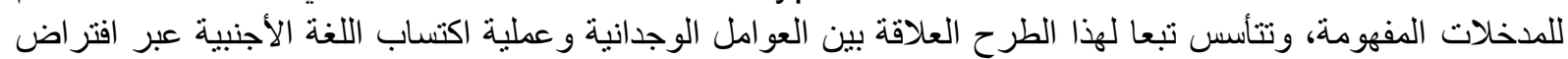

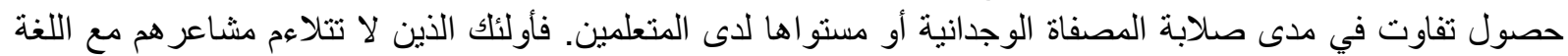

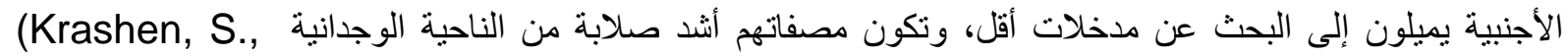
1985, p. 81)

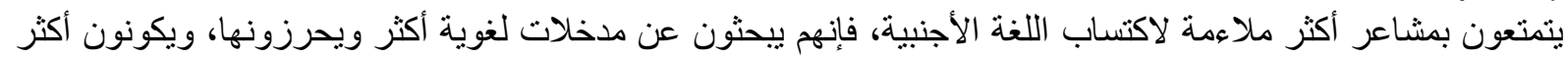

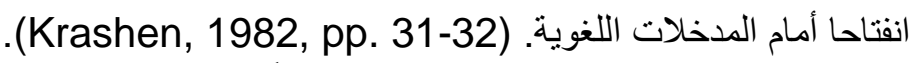

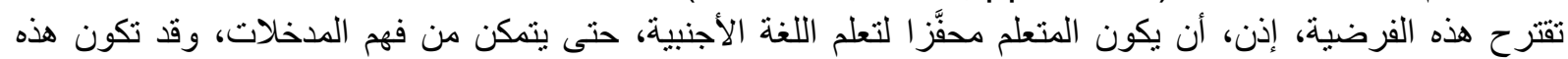

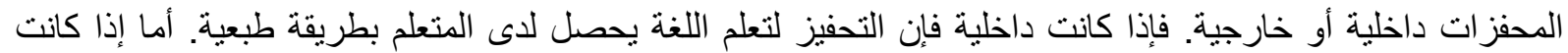

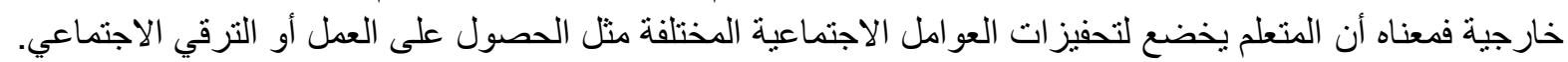

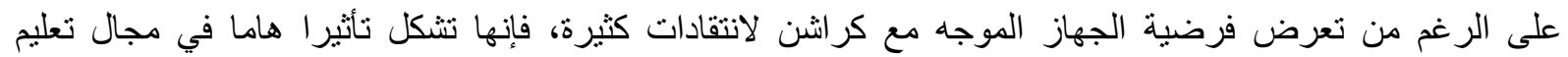

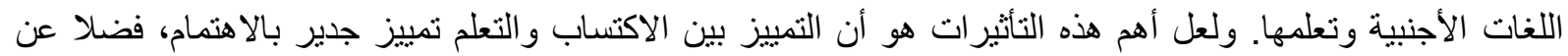

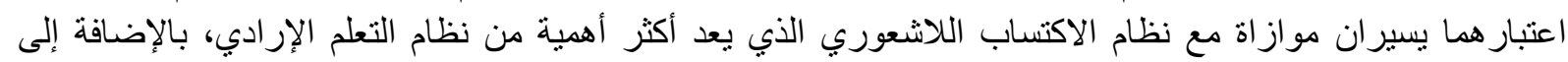

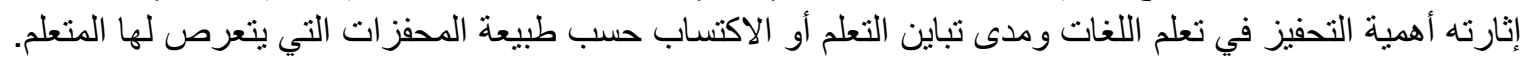


ذارتبطت المقاربة التواصلية ئه Approach Communicative في نشأتها بتغير استراتيجي شمل النظرة إلى اللغة

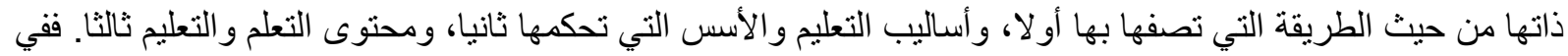

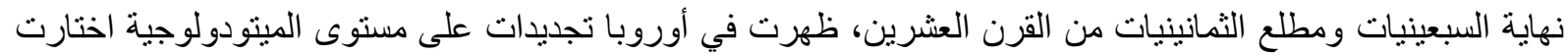

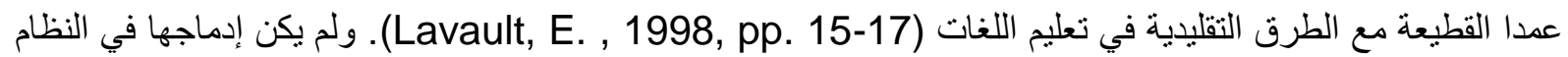

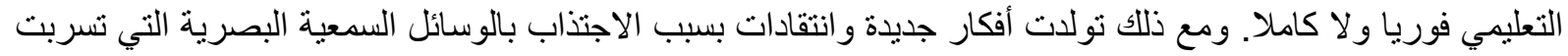

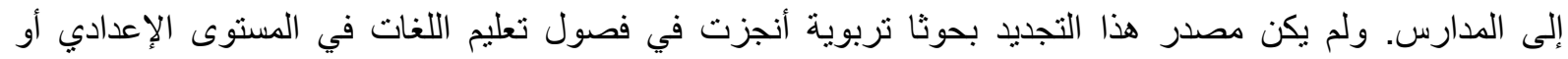

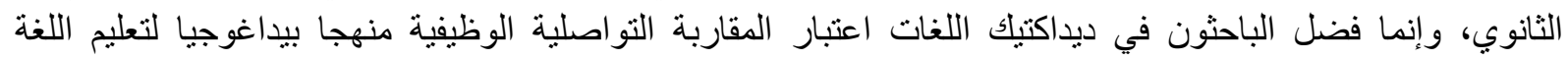

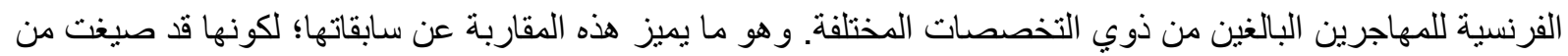

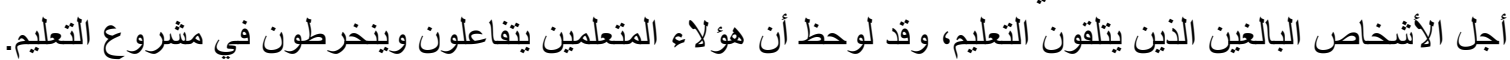

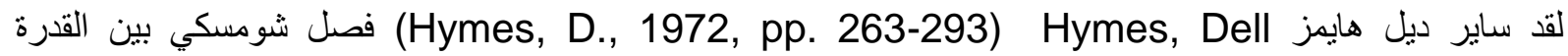
والإنجاز، بل أضاف إليهما مفهوم القدرة التواصلية Communicative competence، أو ملكة التواصل Communicative faculty التي يتصور ها عبارة عن قدرة واحدة تتألف من شقين أحدهما يتعلق باللغة

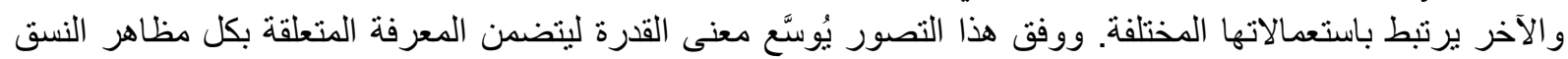

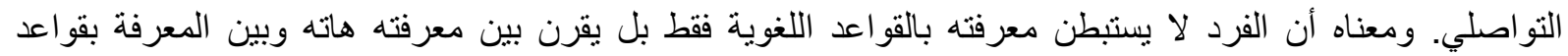
التوظيف في التعبير عن الوظائف اللغوية.

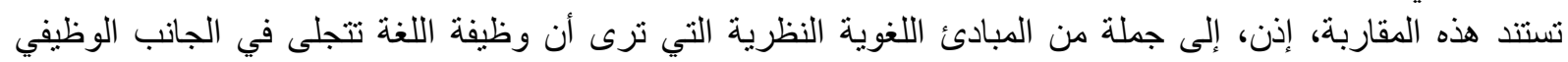

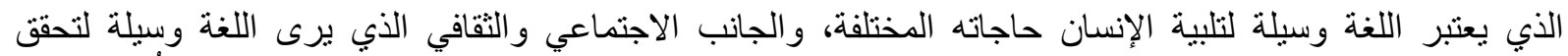

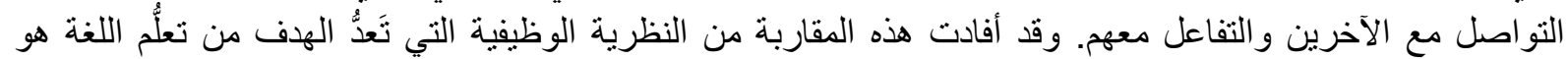

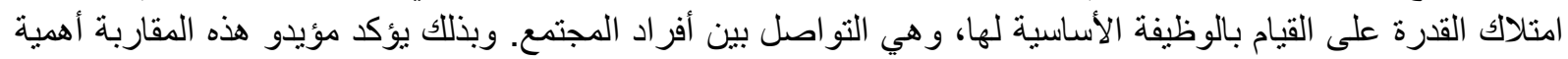

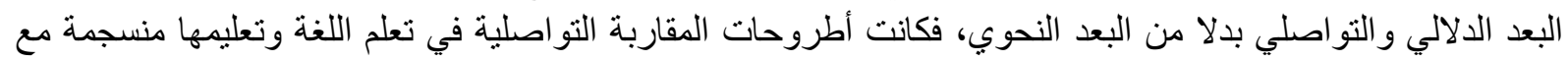

هذه النظرية.

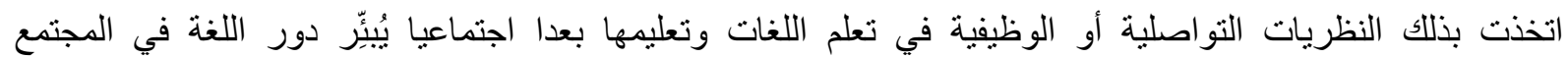

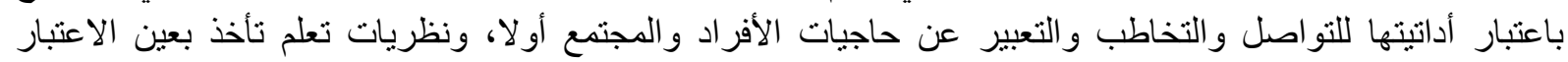
المتعلم ثانيا، بجعل أهداف التعليم تتو افق مع أهداف المتعلمين بعد تحليل احتياجاتهم اللغوية.

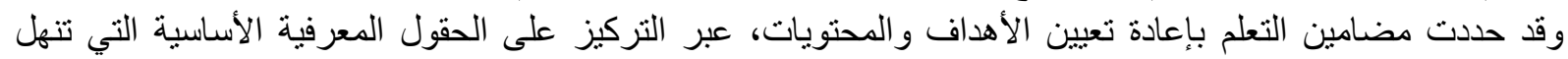

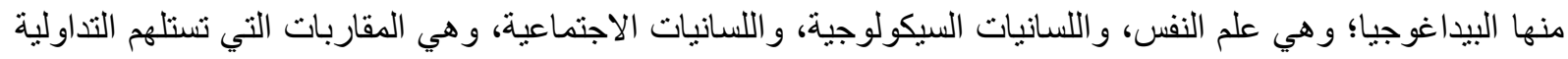

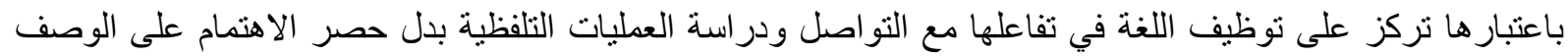

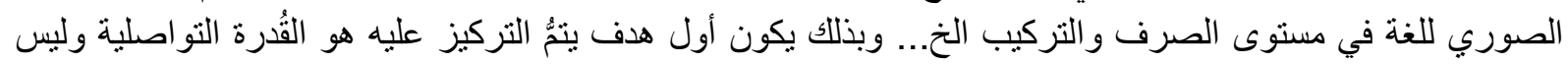
القدرة اللغوية، لأنهما معا يكونان نسقا واحدا ويتطوران بالطرق ذاتها. ويُير هن هذا الهدف على أن المتعلمين المعنيين

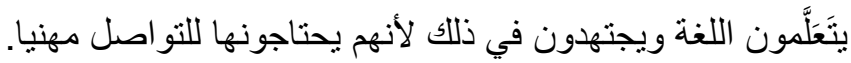

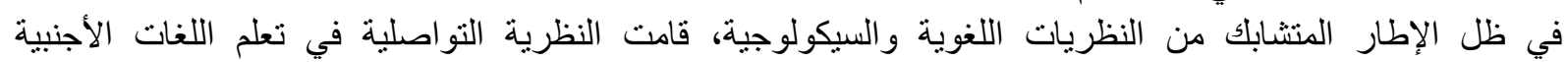

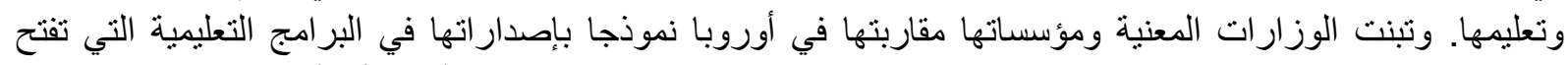

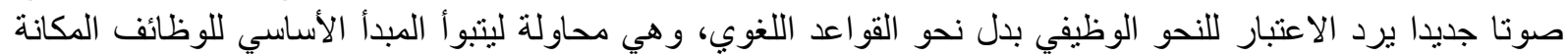

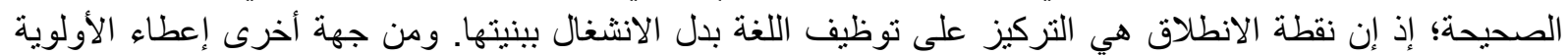

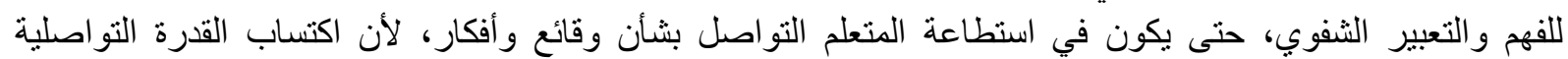

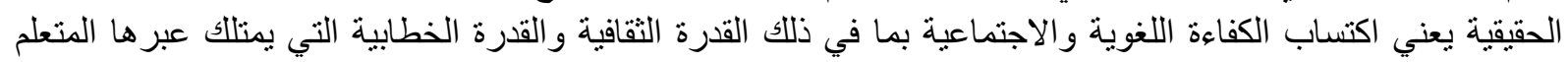

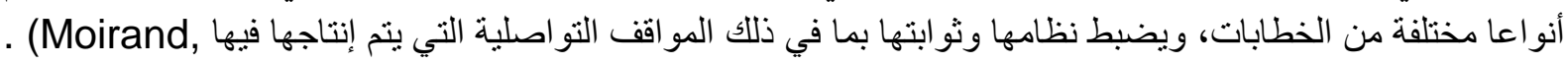

S., 1982, p. 20)

تتركز أسس تعليم اللغات الأجنبية وفق تصور هذه المقاربة في اعتبار المعنى أساسيا؛ فتعلم اللغة هو تعلم التواصل؛

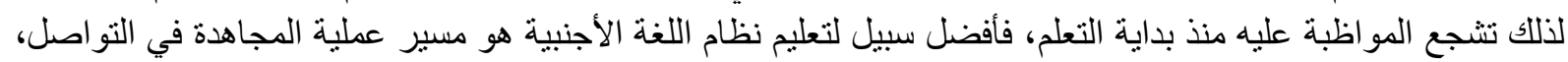

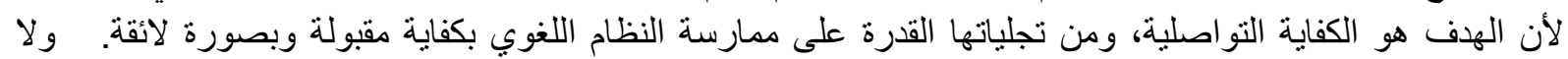

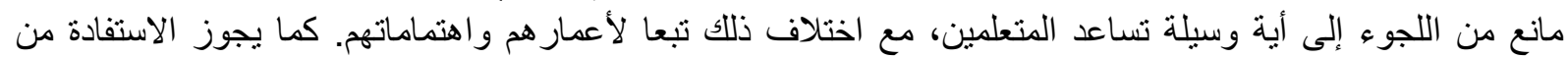


الترجمة إذا استدعت حاجة المتعلمين الاستفادة منها؛ لأن الفصاحة ومقبولية اللغة هما الهدفان الأساسيان. و لا يتم الحكم

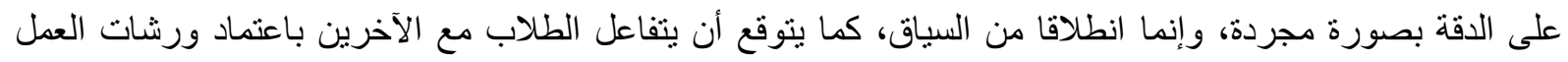
الثنائي أو الجماعي أو عبر إنتاجاتهم الكتابية.

\section{تعايش ديداكتيك اللغات الأجنبية مع تدريس الترجمة}

تعرف الترجمة الممارسة في تعليم اللغات بتسميات مختلفة، منها الترجمة المدرسية والترجمة الديداكتيكية والترجمة

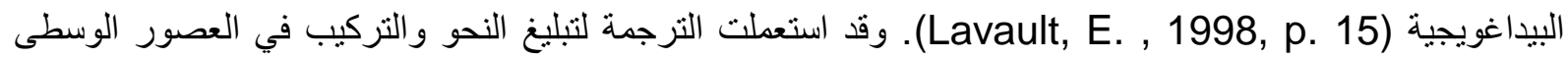

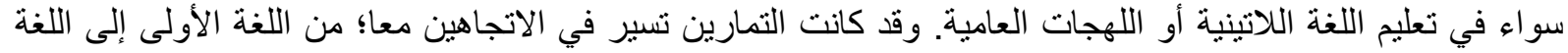

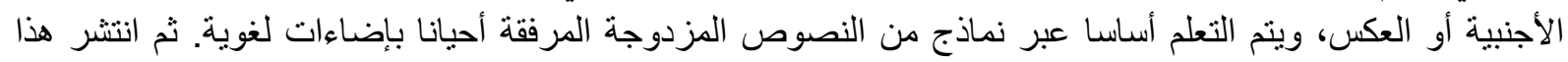

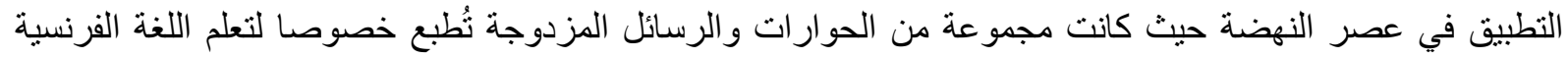
في انجلترا. ثم شهد القرن التاسع عشر فيما بعد بروز مقاربة في تعلم اللغات تعتمد أساسا على الترجمة، وهي "مقاربة النحو

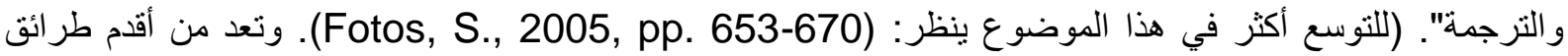

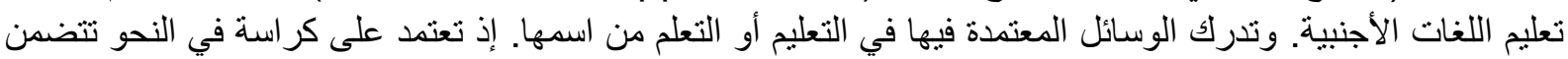

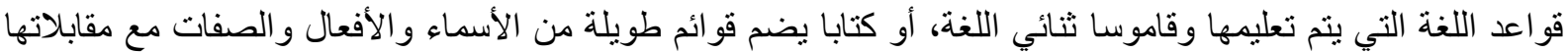

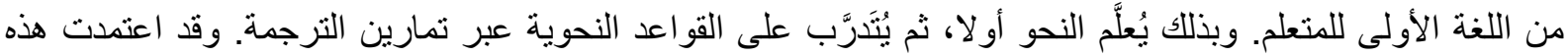

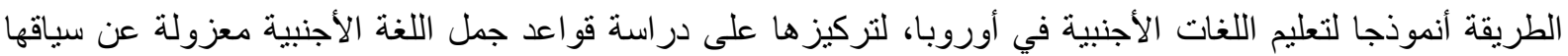

طرحت مناقثات بخصوص جدوى فذو هذه الطريقة الديداكتيكية التقليدية وأهميتها في النصف الثاني من القرن التاسع

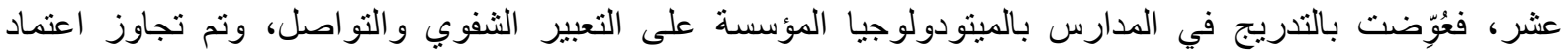

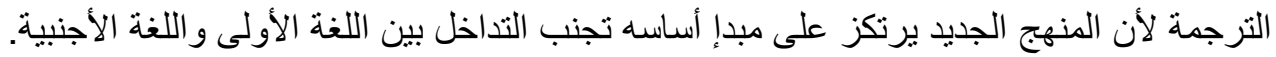

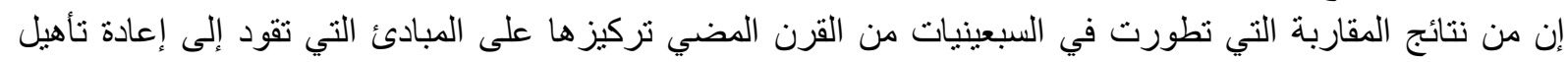

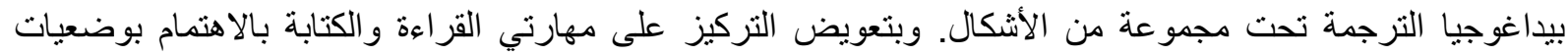

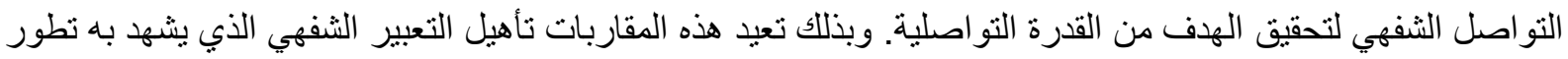

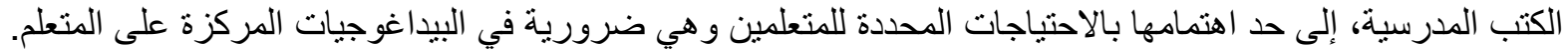

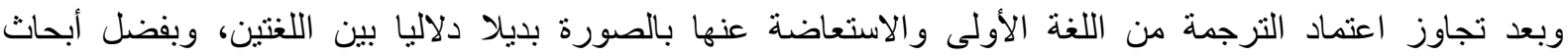

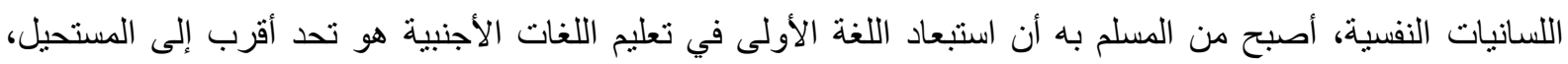

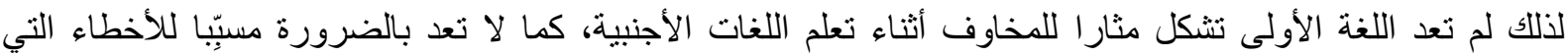

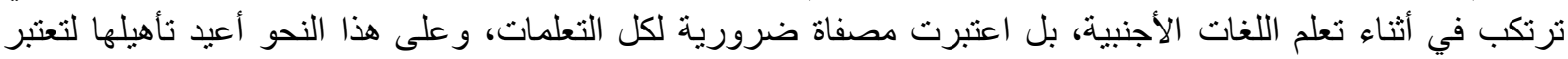
وسيطا لعبور الاتجاه للوصول إلى اللغة الأجنبية.(Gallisson, R., 1980, p. 97) .

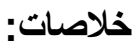

مكنتا استصحاب مختلف المقاربات السابقة من الوقوف على مجموعة الافتراضات التي أقامتها لإشكال تعليم الإني اللغات الأجنبية، بالتركيز على التي تستحضر اللغة الأولى، ورصد الأسس التي تستند إليها واكتشاف القواسم المشتركة

بينها.

يتحقق هذا الهذف بدراسة ظاهرة الأخطاء في إطار علمي يتفق مع النظريات اللسانية ونظريات التعلم وتحليل الأخطاء

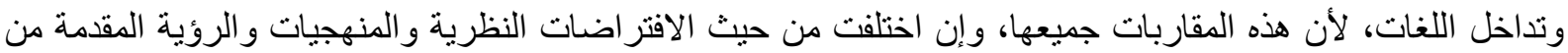

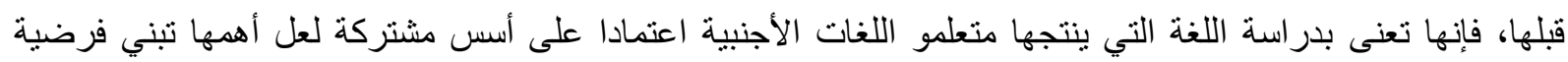

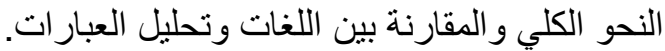

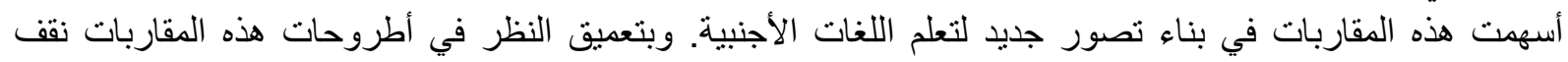

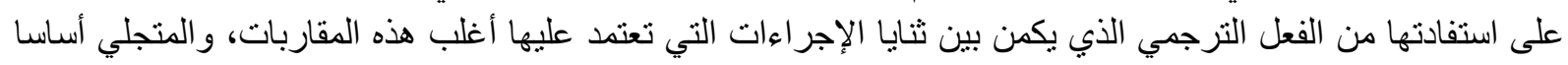

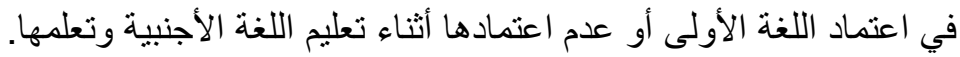


يلاحظ أن القصور العميق في اللغة الأولى ينعكس على تعلم اللغات الأجنيية. وتعد المهارات الثنفوية المتحققة في اللغة

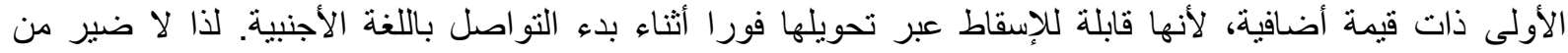

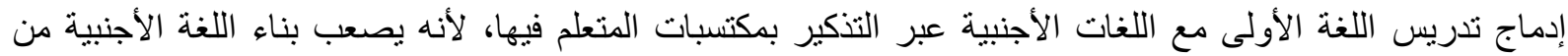
الصفر دون اعتبار اللغة الأولى، وبمقارنة اللغتين بتعلمهما المتعلم معا.

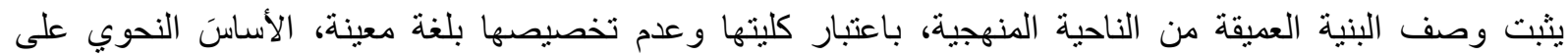
مستوى الخصائص الدلالية و الصوتية، مما يسهل رصد أوجه التشابه و الاختلاف بين اللغتين بطريقة موحدة. مما يستدعي التفكير في اعتماد الترجمة باعنبار ها لغة واصفة بصيغة عرضية أنثاء إنجاز درس تعليم اللغات الأجنبية، و أداة انعكاس التاس

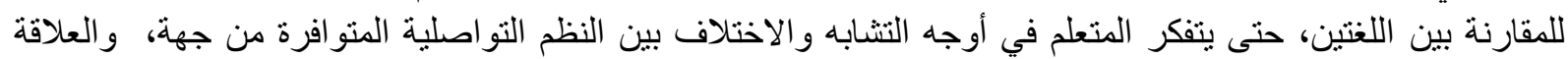
بين معرفة اللغة الأولى وتعلم اللغة الأجنبية، وتحديدا الجانب المرتبط بالقو العيه العد النحوية من جهة ثانية.

\section{Bibliography}

A.P.R., Howatt. (1984). A History of English Language Teaching. Oxford. Oxford: Oxford University Press.

Boers, F., \& Darquennes, J.R. (2007). Multilingualism and Applied Comparative Linguistics: Pedagogical Perspectives (1st ed.). Cambridge: Cambridge Scholars Publishing.

Catford, J. C. (1965). A linguistic theory of translation: An essay in applied linguistics. Oxford: Oxford University Press.

Chau, T. (1975). Error Analysis, Contrastive Analysis, and Students' Perception: A Study of Difficulty in Second-Language Learning. International Review of Applied Linguistics in Language Teaching , 13 (1- 4), pp. 119-143.

Cook, V. (2010). The Relationship between first and second language learning. The continuum companion to second language acquisition. Bloomsbury: Bloomsbury Academic.

Corder, S. P. (1967). The Significance of Learner's Errors. International Review of Applied Linguistic. International Review of Applied Linguistic., 5(1), pp. 161-170.

Corder, S. P. (1973). Introducing Applied Linguistics. Hamondsworth: Penguin.

Corder, S. P. (1981). Error analysis and interlanguage. Oxford : Oxford University Press.

Dulay, H. M. Burt, \& Krashen, S. (1982). Language Two. New York: Oxford University Press.

Ellis, R. (2015). Understanding Second Language Acquisition. Oxford: Oxford University Press.

Fotos, S. (2005). Traditional and Grammar Translation Methods for Second Language Teaching. Dans E. H. (Ed.) (Éd.), Handbook of Research in Second Language Teaching and Learning (pp. 653-670). Mahwah, New Jersey; London: Lawrence Erlbaum Associates.

Fries,C. (1945). Teaching and Learning English as a Foreign Language. Ann Arbor: University of Michigan Press.

Gallisson, R. (1980). D'hier à aujourd'hui, la didactique des langues étrangères, du structuralisme au fonctionnalisme. Paris : Clé international. 
Gass, S. M., \& Selinker, L. (2008). Second Language Acquisition: An Introductory Course. New York \& London: Routlege Taylor \& Francis Group.

Halliday, M., McIntosh, A., \& Stevens, P. . (1964). The Linguistic Sciences and Language Teaching. London: Longman.

Hoey, M., \& Houghton, D. (1998). Contrastive Analysis \& Translation, in Baker, M., \& Malmkjær, K.The Routledge Encyclopedia of Translation Studies. In M. \&. Baker, The Routledge Encyclopedia of Translation Studies. London \& New York: Routledge.

Hymes, D. (1972). On communicative competence. (N. \&. Pride, Ed.) Sociolinguistics.

James, C. (1980). Contrastive Analysis. London: Longman.

Jespersen, O. (1904). How to Teach a Foreign Language. London \& New York: Routledge. London \& New York: Routledge.

Joseph, J. E. (2004). From Whitney to Chomsky: Essays in the History of American Linguistic. Amsterdam \& Philadelphia: John Benjamin.

Krashen, S. . (3003). Principles and Practice in Second Language Acquisition. Oxford: Pergamon Press.

Krashen, S. (1981). Second Language Acquisition and Second Language Learning. Oxford: Pergamon Press.

Krashen, S. (1981). Second Language Acquisition and Second Language Learning. Oxford: Pergamon Press.

Krashen, S. (1982). Principles and Practice in Second Language Acquisition. London: Pergamon Press.

Krashen, S. (1985). The Input Hypothesis: Issues and Implications. London: Longman.

Krzeszowski, P. T. (1990). Contrasting Languages: The Scope of Contrastive Linguistics. New York: Mouton de Gruyter.

Lado, R. \& Arbor, A. (1957). Linguistics across cultures: Applied Linguistics for Language Teachers. Canada: Univ of Michigan Press.

Lado, R. (1964). Language teaching: a scientific approach. USA: McGraw-Hill.

Lavault, E. . (1998). Fonctions De La Traduction En Didactique Des Langues : Apprendre une langue en apprenant à Traduire. Paris: Didier érudition.

Lee, W.R. (1968). Thoughts on Contrastive Linguistics in the Context of Foreign Language Teaching. Wachington D.C: Georgetown University Press.: D.C: Georgetown Unierity Press.

Moirand, S. (1982). Enseigner à communiquer en langue étrangère. Paris: Hachette.

Niklove, M. (2009). The Age Factor and Early Language Learning. Studies on Language Acquisition. Berlin: Mouton de Gruyter.

Puren. (1994). La didactique des langues étrangères à la croisée des méthodes. Essai sur l'éclectisme. Paris: Nathan.

Puren, C. (1988). Histoire des méthodologies de l'enseignement des langues. CLE international (première et deuxième parties). Paris: Nathan.

Robinson, P., \& Ellis, C. (2008). Handbook of Cognitive Linguistics and Second Language Acquisition. NewYork: Routledge. 


\section{APPLIED LINGUISTIC APPROACH TO TEACHING FOREIGN \\ LANGUAGES THEORETICAL AND METHODOLOGICAL MODELS}

Selinker, L. ((1971-b-)). A brief reappraisal of contrastive linguistics. In R. W. (eds.) (Ed.), Proceedings of the Pacific Conference. Honolulu: University of Hawaii Press.

Selinker, L. . (1992). Rediscovering Interlanguage. London: Longman.

Selinker, L. (1969). Language Transfer. General linguistics, 9, pp. 67-92.

Spada, N., \& Lightbown, P, M. (2002). Second Language Aquisition. (N. Schmit, Éd.) An Introduction to Applied Linguistics.

Strevens, P. S. (n.d.). Two Ways of Looking at Error Analysis. Washington: D. O : Centre for Applied linguistics.

Wardhaugh, R. (1970, March 18-21). The Contrastive Analysis Hypothesis. The fourth annual TESOL, Convention. San Francisco. 4(2), pp. 123-130. California: TESOL Quarterly. doi:doi:10.2307/3586182

Wolfgang, K. (1989). L'acquisition de la langue étrangère. Paris : Armand colin. 